This is a so-called personal version (author's manuscript as accepted for publishing after the review process but prior to final layout and copyediting) of the article:

Cornelissen, Joep, Mantere, Saku and Vaara, Eero.2013. The contraction of meaning: the combined effect of communication, emotions and materiality on sensemaking in the Stockwell shooting. Journal of Management Studies, forthcoming.

Researchers are kindly asked to use the official publication in references.

\title{
THE CONTRACTION OF MEANING: THE COMBINED EFFECT OF COMMUNICATION, EMOTIONS AND MATERIALITY ON SENSEMAKING IN THE STOCKWELL SHOOTING
}

\author{
Joep P. Cornelissen \\ VU University Amsterdam
}

\author{
Saku Mantere \\ Hanken School of Economics \\ and

\section{Eero Vaara} \\ Hanken School of Economics \\ EMLYON Business School
}

\begin{abstract}
Acknowledgements: we are grateful for the editorial guidance and very helpful feedback from the editor, Davide Ravasi, and three reviewers of this Journal. We also appreciate previous comments and suggestions from seminar participants at the Universities of Zurich and Leeds, Copenhagen Business School and HEC Paris.
\end{abstract}

Address for correspondence: Joep Cornelissen, Department of Management and Organization, Faculty of Economics and Business Administration, VU University Amsterdam, email: j.p.cornelissen@vu.nl 


\begin{abstract}
In this article, we seek to understand how individuals, as part of a collective, commit themselves to a single, and possibly erroneous, frame, as a basis for sensemaking and coordinated actions. Using real-time data from an anti-terrorist police operation that led to the accidental shooting of an innocent civilian, we analyze how individual actors framed their circumstances in communication with one another and how this affected their subsequent interpretations and actions as events unfolded. Our analysis reveals, first of all, how the collective commitment to a framing of a civilian as a terrorist suicide bomber was built up and reinforced across episodes of collective sensemaking. Secondly, we elaborate on how the interaction between verbal communication, expressed and felt emotions and material cues led to a contraction of meaning. This contraction stabilized and reinforced the overall framing at the exclusion of alternative interpretations. With our study we extend prior sensemaking research on environmental enactment and the escalation of commitment and elaborate on the role of emotions and materiality as part of sensemaking.
\end{abstract}

Keywords: sensemaking, framing, commitment, emotions, sensegiving, materiality 
In organized activity, commitment to a frame - as opposed to being open to and exploring alternative framings - has been suggested as an important source of sensemaking failure in the context of novel, unprecedented circumstances that require inferential flexibility and improvised behaviors (Weick 1993, 2010; Weick et al. 1999; Snook 2000; Weick and Sutcliffe 2003, 2007). In this paper, we explore how such commitment to certain frames builds up and escalates within a series of communicative interactions between experienced professionals. A general characteristic of sensemaking is that the world does not present itself directly in its "raw form"; rather, individuals actively construct it using available cognitive frames that ground their perceptions, thoughts and behavioral actions (Cornelissen and Clarke, 2010; Weick et al. 2005; Maitlis and Sonenshein 2010). The implication is that the ability of individuals in organizations to either fail or succeed in their coordinated actions depends on the way in which they, individually and collectively, cognitively frame and potentially reframe their circumstances as a basis for action (Weick 1993a,b, 1995; Taylor and Van Every 2000).

Prior research has highlighted the role and importance of language, including conventional codes and idiomsas a crucial mediating mechanism between individuals in real time sensemaking, specifically in terms of how they understand the framing of a situation as it unfolds (Maitlis, 2005; Weick, 1988; Weick and Roberts, 1993). In particular, sensemaking research has over the years documented the effects of an over-reliance by individuals on taken-for-granted social labels and common categories as default frames, with at times disastrous consequences (Vaughan, 1986; Weick, 1988, 1993). However, our understanding of how such commitment is established (Weick, 1988, 1993a,b), within and as a result of communication is still limited (Maitlis and Sonenshein, 2010; Weick, 1988, 1993a,b). Weick (1988) initially referred to a process whereby a provisional framing gains strength and certainty with each mention over time. This account, however, lacks theoretical specificity in terms of the role of language and the dynamics of communication and is also largely silent on the impact of emotions (Maitlis and Sonenshein, 2010) and materiality (Stigliani and Ravasi, 2012) on this process.

The main objective in this paper is therefore to elucidate how commitment to certain frames builds up and escalates within a series of communicative interactions. We use the case of the shooting of Jean Charles de Menezes, also known as the Stockwell shooting, as a generative case. The analysis of the case allows us to integrate processes of communication, emotional turmoil and materiality into a model of escalating commitment in sensemaking under pressure. 
By so doing, our model explains how commitment to a frame builds up and may come to overrule reflective thought. Our analysis thus adds to previous research that has not specified the processes leading to commitment to particular frames (Maitlis and Sonenshein, 2010; Weick, 1988, 1993b). Moreover, by integrating explanations related to communication, emotion and materiality, our analysis helps to better understand the dynamics of these crucial inter-linked aspects of sensemaking.

\section{THEORETICAL BACKGROUND}

The theoretical backdrop for our study is the extensive literature on sensemaking under pressure (Weick 1988, 1993a,b, 1995; Quinn and Worline 2008; Maitlis and Sonenshein 2010). Sensemaking under pressure relates to organizational conditions where individual actors need to

make timely and swift decisions and where the consequences of their decisions have a high impact (Weick, Sutcliffe and Obstfeld, 1999). If not anticipated, such sensemaking may translate into accidents or disasters that have consequences for stakeholders. Examples include the Bhopal gas leak (Weick, 1988, 2010) and the Bristol Royal Infirmary cardiac surgery (Weick and Sutcliffe, 2003). It may also present the sensemaking actors themselves with loss of or threats to their personal wellbeing (Weick, 1990, 1993a; Whiteman and Cooper, 2011). Quinn and Worline's (2008: 501) study of the hijacking of United Airlines flight 93, for example, involved a "shocking and incomprehensible" event where passengers had to recover a sense of what it meant to be in the midst of a terrorist "suicide mission" that posed a direct threat to their lives.

\section{Framing in Sensemaking}

Sensemaking aims to understand how the framing of decisions in event sequences guides and directs individual and collective cognitive inferences and behaviors (Weick 1993; Weick and Roberts 1993; Taylor and Van Every 2000; Maitlis and Sonenshein 2010). Sensemaking has been defined as the attribution of meaning to a target (experiences, events or other stimuli) via the placement of this target into a mental model or framework, otherwise known as a frame (Pratt, 2000; Weick, 1995). As Weick (1995: 109-111) suggests, sensemaking involves a frame, a cue and the relational connection made between them. "Less abstract words" designating and labeling specific cues, as reference points, are seen to point in a relational sense to "more abstract frames" (Weick, 1995: 110). This implies that when for example individuals use specific words as part of their sensemaking, these do not strictly encode or determine meaning. Instead, words 
prompt larger background frames, or cognitive schemas, that guide interpretations and actions. This also means that in ongoing interaction individuals need to detect the changing background assumptions, or schemas, necessary for continued interpretation (Goffman, 1974, 1981; Tannen, 1985), "with [such] frames providing an interpretive 'footing' that aligns schemas that participants to the interaction bring with them" (Benford and Snow, 2000: 614; Goffman, 1974, 1981).

Another important characteristic of the role of frames within sensemaking is that they impart organizing structure. Simply put, the frames individuals use as part of their sensemaking define situations and the structure of experiences associated with them (Goffman, 1974; Snow et al., 1986). Benford and Snow (2000: 614) argue that "frames help to render events or occurrences meaningful and thereby function to organize experience and guide action". For example, when the firefighters in the Mann Gulch case had been prompted to define the raging fire as a " 10 o'clock fire" they incorrectly categorized it as a fire that would be under control and out by 10 o'clock the next day (Weick, 1993a). Activating a frame thus creates expectations about important aspects of the context or circumstance by directing individuals to elaborate on the default or prototypical scenario in a manner suggested by the frame (Lakoff 1987). Furthermore, frames help individuals to comprehend and predict the behavior of others through stereotypical inference and, as such, support coordinated collective action, providing individuals commit themselves to playing out the jointly framed situation (Gioia and Poole 1984; Pentland and Reuter 1994).

\section{Commitment to Frames}

When organizational members need to coordinate their actions in unexpected situations, they construct a common frame in a step-by-step manner as events evolve. This observation has been made in studies within groups and organizations situated in contexts of crisis, change and uncertainty (Corley and Gioia, 2004; Maitlis, 2005; Sonenshein, 2010) and similarly applies to studies of the improvised coordination of teams or groups in novel or dynamic circumstances where joint understanding has to be established in real-time (Bechky and Okhuysen, 2011; Faraj and Xiao, 2006; Okhuysen and Bechky, 2009; Quinn and Worline, 2008; Weick, 1993). Faraj and Xiao (2006) demonstrate how open and frequent dialogue among team members in trauma centers facilitated coordination in emergency response operations, over and beyond standard 
procedures. In this and related cases, coordination was effectively accomplished, rather than predesigned, through communication and as the coordinated activity progressed (Bechky, 2003; Quinn and Dutton, 2005). The collective act of building up common ground around a common framing of the situation is crucial to enable coordination between individuals and to ensure that each individual has a sense of what is expected of them (Maitlis and Sonenshein, 2010; Faraj and Xiao, 2006; Weick, 1993; Weick and Roberts, 1993). The resulting commitment to such a frame structures understanding, provides purpose and direction (Christianson et al., 2009; Maitlis and Sonenshein, 2010; Weick, 1993) and a basis for expectations about the interrelated activities that are required as events unfold (Faraj and Xiao, 2006; Quinn and Dutton, 2005).

While commitment 'serves as a foundation for sensemaking' (Maitlis and Sonenshein, 2010:562), it can also act as a double-edge sword. On the one hand, it creates meaning and purpose and enables coordinated activity, and may thus facilitate sensemaking under pressure (Maitlis and Sonenshein, 2010). On the other hand, "such staunch commitment to a particular set of meanings creates substantial blind spots that impede adaptation" (Maitlis and Sonenshein, 2010: 562). Whilst commitment is an important basis for sensemaking, it may also entrap sensemakers and impede their ability to be mindful as commitment to a particular frame escalates (Maitlis and Sonenshein, 2010). The problem with an overreliance on any single frame is that frames themselves may be overly brittle (Weick 1995). Wilensky (1986) criticizes frames for being rigid data structures that cannot accommodate events that are out of the ordinary - a point echoed by Weick and Sutcliffe (2007).

Weick $(1988,1995)$ argues that commitment is founded on enacting a particular framing of the environment. He conceptualizes 'enacted environments': processes by which a particular framing is established in prior episodes of communication and as such provides the source for future expectations (Weick 1988, 1995). When a frame is reinforced in inter-linked episodes of communication (what he labels as an enacted environment) and collectively elaborated as a shared commitment, it leads to a strengthening of commitment to a particular frame, which in turn directs and channels meaning construction in real-time. Weick (1988: 307) thus refers to an enacted environment as the "conceptual residue" that is carried over from previous "episodes of talk" and affects subsequent sensemaking. As he suggests, the action of talking conceptually frames circumstances, which then become "preconceptions which partially affect the next episode of talk" and any future episodes of sensemaking. 
We, however, lack understanding of the processes by which commitment becomes established and binds participants to a particular course of action. For example, it may well be that the initial sensegiving of particular actors towards others plays an important, if not decisive, role in directing and constraining meaning construction as it unfolds within a group (Gioia et al., 1994; Maitlis and Lawrence, 2007; Whiteman and Cooper, 2011). Sensegiving refers to the strategic discursive and framing efforts of actors to influence "the sensemaking and meaning construction of others toward a preferred redefinition of organizational reality" (Gioia and Chittipeddi, 1991: 442). We also do not know how 'conceptual residue' is carried over, nor how earlier acts of sensegiving and sensemaking are related in a contingent manner so that these scale up into a collective commitment to a particular framing and course of action at later stages. Moreover, it is likely that the process is not simply cognitive or linguistic, but is generally affected by individuals' prior experience (Mantere, Schildt and Sillince, 2012; Whiteman and Cooper, 2011), emotions (Maitlis and Sonenshein, 2010) and the material contexts of action in which they find themselves (Stigliani and Ravasi, 2012).

Maitlis and Sonenshein (2010) recently highlighted that the role of emotions, whilst prevalent in processes of sensemaking under pressure, has been left largely unaddressed in prior work. Weick (2010: 537) also described his original analysis of Bhopal as 'cool and cognitive', and hinted at alternative analyses and interpretations that would foreground the role of emotions. The limited work that does exist (Bartunek et al., 2006; Myers, 2007; Sonenshein, 2009) largely focuses on the arousal of negative emotions such as fear and anxiety at the individual level, but has not yet covered how emotions dovetail with collective sensemaking processes. Following the call by Maitlis and Sonenshein (2010) and Weick (2010) for more research on emotions as part of sensemaking, we therefore focus on the arousal and effect of emotions on individual and collective sensemaking as part of our case (see also Huy, 2002: Walsh and Bartunek, 2011).

Furthermore, following Whiteman and Cooper (2011), sensemaking and sensegiving also involve physical gestures or demonstrations from one person to the next (what they label as sensegiving-in-action). We expect however that besides physical, embodied gestures and acts, materiality may also play other roles in sensemaking. We thus consider materiality in an enlarged sense in this paper by focusing on the material environment or surroundings in addition to physical artifacts or objects (Stigliani and Ravasi, 2012) and embodied acts of gesturing (Whiteman and Cooper, 2011; Maitlis and Sonenshein, 2010). 
The ability of sensemakers to transcend the commitment to any particular frame - to 'update' and 'doubt' (Maitlis and Sonenshein, 2010: 565-566) - is crucial to adaptive sensemaking in context. The concept of 'adaptive sensemaking' refers to the ability of sensemakers to query an initial frame and commitments, and to mobilize instead an alternative frame from background knowledge or make novel associations as a way of structuring expectations and make inferences (Bechky and Okhuysen, 2011; Maitlis and Sonenshein, 2010). Previous research has highlighted the potential role of an inquiring mind and surprise or doubt as key conditions in this respect, enabling individuals to shift between frames, or at least leave open the possibility for an alternative and 'updated' version of events (Christianson et al., 2009; Hare and Roberts, 2010; Weick, 2010). In this paper we are interested in further exploring when and how such adaptive sensemaking is triggered or enabled in the face of a previously built up collective commitment to a frame.

\section{Research Question}

We formulate our research question as follows: What are the processes that make individuals commit themselves to a specific frame in collective settings of inter-linked sensemaking, at the expense of more adaptive sensemaking? We believe answering this question will be an important step towards solving the perennial research question on sensemaking under pressure (Maitlis and Sonenshein, 2010; Weick, 1993a; Weick, 2010); namely, how it is that individuals, as part of a collective, are at times able to think laterally and improvise rather than committing themselves to a single, and possibly erroneous, frame. We employ a generative case (Weick, 2007) that puts these processes into relief and allows us to formulate a set of theoretical explanations to answer our research question.

\section{CASE STUDY AND METHODS}

The shooting of Jean Charles de Menezes on 22 July 2005, an incident also known as the Stockwell shooting, presents a prototypical case of collective sensemaking under pressure (Flyvberg 2006; Weick 2007). A critical characteristic of the operation was that it involved timelimited processes of communication and distributed sensemaking in stressful, fast-changing circumstances where the individual officers were not physically co-present (Weick and Sutcliffe 2007; Roberts et al. 2008) and where the scale of consequences of their sensemaking precluded

any trial and error learning through experimentation (Weick et al. 1999). Specifically, the 
terrorist suspect could not be approached unless it was confirmed that he was the target, which in turn would mean that he would be preemptively shot. Any alternative actions could alert the suspect to the presence of the police, risking the detonation of a bomb. These particular conditions not only put enormous pressures on police officers to get the identification right, but arguably also necessitated a degree of flexibility to allow for improvisation in a volatile environment that carried the potential for error (Weick et al. 1999; Roberts and Bea 2001; Faraj and Xiao 2006).

The operation uniquely relied on flexible on-line communication, as opposed to a system of code words or routines not yet been developed for "spontaneous" suicide bombing incidents. The Metropolitan Police argues that for this kind of operation the "use of plain language to convey critical decisions" and "clear words of command" is more critical than a system of code words (MPS/MPC, responses to Rule 43 (inquest recommendations), February 2009). Besides setting up a command and control structure, the operation itself was not pre-scripted, and the officers themselves had to construct an understanding of the individual subjects they were following. The operation was also a dynamic and fast-moving one, involving different areas in the city of London. These particular characteristics of the case make it ideal for our theory-building

purposes. It allows us to systematically explore, first, how and why particular instances of communication led to commitment to specific frames; second, how emotional arousal affected this commitment; and, third, how interpretations of material cues impacted this sensemaking and commitment.

\section{Data}

The primary data for our analysis come from the extensive and detailed evidence gathered during the so-called Stockwell inquest into the events leading up to the shooting of Mr De Menezes. In England and Wales an inquest is an official investigation of any death where public servants, e.g., police officers, may be implicated. The purpose of this kind of inquest is to establish in a public and factual manner how the death occurred. Inquest data from other events have been previously used in sensemaking research (Brown, 2003, 2005; Gephart, 1984, 1993). Connected to their jurisdictional premise, inquest data include retrospective sensemaking accounts (Brown, 2003, 2005), although in the context of our study we focus primarily on recorded real-time 
instances of sensemaking on the day of the shooting. Where we introduce post hoc recollections or accounts of officers involved in the shooting, we clearly mark this in the analysis.

We first downloaded the transcripts of the evidence in the inquest proceedings and converted these into text files. The proceedings started on the 22 September 2008 and concluded on December 4 of that same year. There were a total of 48 transcript documents from the days in which testimonies and evidence were recorded. In total, 73 witnesses gave evidence during these proceedings, including the police officers involved in the operation on the day as well as expert witnesses such as forensic examiners and anti-terrorism experts. We saved these files as a single corpus, defined as "a relatively large collection of naturally-occurring texts which have been stored in machine-readable form" (Deignan 2005: 76). We used the Oxford Wordsmith software to aid with the analysis of the words and expressions that were used by police officers in the operation. Wordsmith is adept at navigating across a large collection of texts (Gephart 1993, 1997). Our analytic strategy for these texts was based on interpretive analysis (Gephart, 1993, 1997) that "seeks to develop or recover themes, meanings and patterns in textual data; to provide 'thick' interpretations which display how concepts are operative in the data; and to ground theory in data in an ongoing or iterative process of analysis" (Gephart, 1997: 585).

The software enabled us to simultaneously process all of the transcribed files for key words or expressions used in the operation (cf. Gephart, 1993, 1997). This was helpful in providing background information for interpreting the word or expression in context and for triangulating across the sources of evidence and witness testimonies. In addition to analyzing the verbal transcripts in this manner, we consulted the material evidence directly referenced in the transcripts, both of which are publicly available (previously at http://www.stockwellinquest.org.uk and now at http://www.julyseventh.co.uk/j7-jean-charles-demenezes-inquest/index.html). This evidence includes 1012 separate files with photos, excerpts of logged accounts, police documents and records of telephone conversations on the day. We used the transcripts as the primary data for our analysis, with the additional material evidence used to corroborate our analysis.

The evidence recorded in the transcripts gives a direct record of the real-time communication between police officers, indicating their sensemaking from the moment Jean Charles de Menezes left his house to the point where he was shot. Triangulation across these sources of real-time data 
and across the testimonies of individual police officers confirms the essential events on that day and the experiences of police officers during the operation (as they recollected them afterwards). In fact, after weeks of taking evidence, the presiding judge over the inquest proceedings, expressed in his summing up to the jury that the compiled evidence was comprehensive, saying "we are as sure as we can be that there is nothing more of any materiality or relevance that could be put before you" (December 2 transcript, page 43). This level of support for the detail of the primary data is sufficient for our purpose of developing theory on real-time sensemaking in the context of an unprecedented, complex and dynamic situation that required a reliable and resilient organizational performance (Weick et al. 1999).

Our ontological and epistemological position in this study can best be characterized as a version of critical realism that focuses attention on the crucial role of communication in the social construction of reality, but places this communication in its socio-material context (Fairclough, 2005; Vaara and Monin, 2010). We consider frames, as part of sensemaking, as analogue structures, or hypothetical models, that are constructed by individuals and provide them with a basis for interpretation. Likewise, emotions may be aroused and expressed as part of sensemaking, but, as in our case, are not necessarily directly representative of the objective circumstances in which individual officers found themselves. At the same time, the material environment exists in a real physical sense outside of the individual officers as embodied agents. However, how they read and interpret this environment is again an act of constructing, or conceptualizing, an understanding. Our analysis also includes pragmatist elements in the sense that we pursued an abductive approach (Locke et al. 2008; Ketokivi and Mantere 2010) where alternative counterfactual explanations (Durand and Vaara, 2009) played a key role in our theory development (as explained below).

\section{Data Analysis}

For our analysis, we used a grounded theorizing strategy (Langley, 1999) and followed an abductive approach where emerging theoretical ideas were refined alongside increasingly detailed empirical analysis (Locke et al. 2008; Ketokivi and Mantere 2010; Mantere and Ketokivi, 2013). An abductive research design is an iterative process, where data and theory are examined in tandem in an effort to solve a stated mystery (Alvesson and Kärreman, 2007). Multiple candidate explanations or counterfactuals (Durand and Vaara, 2009) are constructed 
from the theoretical discourse on sensemaking, and interrogated against the data to provide a credible solution to the mystery (Ketokivi and Mantere, 2010). In our case, the mystery was tangible: What would explain the tragic outcome of the Stockwell shooting? How could the sensemaking of officers on the job that day, lacking sufficient evidence to support drastic action (i.e., no positive identification), result in such an outcome?

Our analysis proceeded in three stages. The first stage of our analysis involved the construction of a detailed mapping of the key events and sensemaking episodes, as based on the available data (Langley 1999). We drew largely on logged accounts and records from that day. Second, to better understand the background to the decisions that were made and the experiences of the police officers on the day, one of the authors attended the inquest proceedings. Lastly, we all studied the submitted evidence on police protocols.

In the first, stage, based on the initial mapping of events, we bracketed three key episodes in the case (Langley, 1999) and singled out significant decisions that appeared to be turning points in the case, such as the order that was given to the firearms officers to "stop" De Menezes. We parsed each of these episodes, taking into account the sensemaking and coordination of different officers, as part of the overall operation.

Insert Table 1 about here

The first episode that we identified involved sensemaking about the identification of the subject, covering the period from when De Menezes left his house to Commander Dick's decision to mobilize the firearms team (see Table 1). The coordination in this first episode was restricted to the surveillance teams and to Commander Dick and her staff in the control room. The subsequent second episode started with the actual decision to deploy the firearms team. In this episode, firearms officers made sense of the kind of scenario they were in as well as the tactics they should follow in relation to the suspect. The coordination of this episode involved Commander Dick and her staff in the control room, the team of firearms officers and a group of surveillance officers who were still shadowing De Menezes. The final episode focuses on the sensemaking of police officers when they approached the suspect in the Stockwell tube station. This episode 
involves the final moments in the station and train carriage when officers come face-to-face with De Menezes in the crowded underground train. Coordination in this instance was restricted to those firearms officers and surveillance officers who had gone into the station and who no longer had any radio contact with the control room. For each of these episodes we relay the sensemaking (cognitive frames), communication and actions of key actors, including Commander Dick, the main operator in the control room ('Pat'), senior surveillance officers ('James' and 'Ivor') and the firearms officers ('C2' and 'C12') who come face-to-face with De Menezes.

In the second stage of our analysis, we mobilized specific theoretical lenses to analyze the data and develop our explanations. The main purpose of doing so was to zoom in on viable interpretations of the case and to ultimately develop a more refined process theory of commitment in sensemaking (cf. Langley, 1999). The explanations we discovered are drawn from the sensemaking literature. Each lens was laid over the data and observations of each of the three episodes in an attempt to explain the sensemaking of the police officers and the decisions and actions that they took. The first, communication lens focused on the role of language in sensegiving and sensemaking (Gioia et al., 1994; Maitlis and Lawrence, 2007; Whiteman and Cooper, 2011) and tuned our analysis to how words and expressions within communication may cue or prompt a cognitive frame, or "schema of interpretation" (Goffman, 1974: 21). In particular, we concentrated on the crucial role of 'linguistic framing', that is the key role that specific words and expressions played in the creation and reinforcement of particular frames as part of ongoing sensegiving and sensemaking.

The second lens focused on the experienced and expressed emotions of the police officers on the day, and how this affected their sensemaking, decisions and actions. This perspective provided an analysis of how certain emotions such as fear and panic (Maitlis and Sonenshein, 2010; Weick, 1993a; Weick et al., 2005) started to consume officers, affecting their decision-making and severely impeding their ability to be reflective and mindful of alternative scenarios to that of closing in on a terrorist suicide bomber. In this analysis, we sought evidence on both emotional arousal at the level of individual officers as well as how emotions were expressed (in language or gestures) and influenced co-interacting officers. Rather than employing an a priori categorization of basic emotions (as in, e.g., Liu and Maitlis, 2013), we coded the evidence on emotions in an iterative and open fashion (as in, e.g. Martin et al. 1998). We drew on prior literature to guide the 
identification of specific emotions and their arousal (Walsh and Bartunek, 2011), yet we also inductively and openly coded the emotional turmoil that the police officers experienced in these extraordinary circumstances. In addition, and consistent with recent research (Huy, 2002: Walsh and Bartunek, 2011), it is important to note that we identified emotions based on individuals' expressions and statements recorded in the inquest proceedings ${ }^{1}$.

The third lens focused on materiality (Leonardi and Barley, 2010; Orlikowski, 2007; Stigliani and Ravasi, 2012; Whiteman and Cooper, 2011) and highlighted the role that materiality played in the sensemaking of police officers. More specifically, we focused on three material aspects: the physical setting or material circumstances in which officers found themselves at various points, their physical demonstrations and gestures towards one another, and the material objects that they had at their disposal such as guns, hollow point bullets and video and film equipment. This analysis drew out the crucial role played by these material cues such as the picture of one of the suspects and the possibilities offered by various locations (e.g., on a bus and in the underground station) in the sensemaking of police officers about possible approaches and armed interventions.

In the third stage of our analysis, we took a further step and reflected on the strength and boundaries of these alternative explanations both separately and in combination to draw out an emergent process model. This resulted in the identification of novel process explanations: communicative grounding (the establishment and reinforcement in communication of a common framing that makes it hard to question let alone suspend or abort an agreed-upon course of action), emotional contagion (the continuous reinforcement and spreading of negative emotions through communication and social interaction that overrules reflective thought) and material

\footnotetext{
${ }^{1}$ Our study consists of data on the real time communication and actions of police officers, but does not include audio-visual recordings that would have allowed us to infer more directly emotional displays (Liu and Maitlis, 2013). And whilst we relied primarily on the real-time sensemaking processes, we did draw selectively on the posthoc accounts of police officers describing their emotional arousal (e.g., fear) at certain points in time. One could argue that based on the timing of accounts it may be possible to draw distinctions between in situ sensemaking and retrospective sensemaking, with the latter being more prone to self-presentation biases. However, there are two reasons to assume that such a distinction is not that significant in our study and that therefore post-hoc accounts are a reliable guide to emotional arousal. First, individuals often cannot retroactively compensate their original encoding and experiences. There may be instances where new evidence becomes available that contrasts with the original encoding, in which case individuals may return to their original account, but instead of fundamentally altering their account, they tend to reprocess it in a more systematic fashion (Lerner and Tetlock 1999). Second, all of the officers were giving evidence under oath, and were thus primed to honestly disclose their emotional experiences at the time.
} 
anchoring (the grounding of conceptualized and expressed frames and emotions in perceived material circumstances and artifacts).

These emergent processes interacted in the case, amplifying the collective commitment of police officers to the framing of De Menezes as a terrorist suicide bomber. In turn, we re-examined the data's fit/misfit with the emergent theoretical understanding and checked for completeness in the trail of evidence. In doing so, we attempted to draw out the transferability of the findings and to extend existing theory on sensemaking, including prior work on commitment, materiality and emotions.

\section{FRAME COMMITMENT IN THE STOCKWELL SHOOTING}

\section{Context}

Two weeks prior to the shooting, the city of London had woken up to a series of coordinated suicide bomb attacks in three underground stations and a bus, killing a total of 52 commuters, 4 suicide bombers, and injuring many hundreds of civilians. The explosions, also called the 7/7 bombings, constituted one of the largest and deadliest terrorist attacks in London. Around noon on July 21, another terrorist cell attempted to explode bombs on three underground trains and a bus. Later that day, Commander McDowall, the Deputy National Coordinator for terrorist investigations, held a meeting with his command team. Because the bombers were still at large it was decided that a specialist firearms team would be on stand-by 24 hours a day to assist in the manhunt for these suspects. Commander Dick was appointed as the designated senior officer (DSO) to lead the manhunt because she had had previous experience with policing large civic operations and had been one of the first senior officers to receive training for "Kratos" operations. Kratos was, and still is, the code word for policies and tactics that were developed for dealing with suspected terrorist suicide bombers. Operations under Kratos, the ancient Greek word for might or strength, allow for pre-emptive police strikes before terrorist crimes and casualties can occur. To incapacitate or kill a suspected terrorist, police officers can fire a critical headshot (rather than the standard practice of firing at the torso), but only when authorized by a DSO. Under Kratos, there is also no need to provide a verbal challenge to the suspect, as this would alert him or her to the presence of the police.

The strategy that Commander McDowall set for the operation involved covert surveillance carried out by surveillance teams, whilst the direct approach of any suspect targets was entrusted 
to special branch (SO12) and specialist firearms officers from SO19, the Metropolitan Police's firearms department. SO12 is the unit charged with national security and counter-terrorist operations; it involves trained officers who would not necessarily use lethal force. SO19 (or CO19) is a unit of highly trained firearms officers who provide firearms-related support. Figure 1 below displays the central actors involved in the operation, including the main lines of communication between them (most of the police officers on the ground, including surveillance and firearms officers, are referred to by codenames to protect their identity). The operation and potential use of the Kratos protocol presented an unprecedented situation for Commander Dick as well as for the other officers in the control room and on the ground. In addition, although individual officers enjoyed close working relationships within the surveillance and firearms teams, they had not previously worked together (transcripts October 6-8) and had as far as the records show not been involved in the events associated with the initial bombings on the $7^{\text {th }}$ of July.

Insert Figure 1 about here

The events unfolded as follows: At around 2:05 on the morning of the shooting, the control center at New Scotland Yard, the headquarters of the Metropolitan Police, received information from one of its forensic teams. The team had found something in a rucksack that carried an unexploded bomb: a gym card with the name Hussain Osman and a photograph. Subsequent investigation at the gym returned the address of 21 Scotia Road in South London as his residence, a building with multiple residential flats. The photo was compared with CCTV footage from the day before, and it was established that Osman was one of the failed bombers. At 4 o'clock in the morning, Commander McDowall developed a strategy to control the premises at that address through covert surveillance, and to follow any person leaving those premises until it was felt safe for special branch (SO12) or specialist firearms officers (SO19) to challenge and stop them. The first of the two surveillance teams took up position just after 6 o'clock in the morning and had been supplied with a copy of the picture from the gym card (see Figure 2 below: copy of evidence D00419 and D441). 
Insert Figure 2 about here

At around 7 in the morning, Commander Dick arrived at New Scotland Yard. Commander McDowall briefed her on the strategy. The firearms team came on duty at 7, booked out their weapons, and received two briefings before they made their way to Scotia Road. At 7:45, they were first briefed by their tactical adviser, Trojan 84, who told them that they might have to use "unusual tactics"; a reference to the possibility of a critical head shot being ordered, and that they should trust the information that they were given, a reference to the central command structure of a Kratos operation. The firearms officers had also been issued with grain hollow point bullets, ammunition designed for the purpose of immediately incapacitating a suspect with a single shot to the head. A further briefing followed at around 8:45 and lasted until 9:15. DCI Purser, who delivered the briefing, referred to the usual police guidelines of reasonable force, but also tried to prepare the firearms officers for the possible threat they might face that day. One of the firearms officers, C12, recalls details of the briefing and how it affected his state of mind (evidence files S353-358):

"Mr Purser had used the following words and phrases to describe the group - 'well prepared', 'up for it', 'deadly and determined'. I was left in no doubt as to the type of suspects we were preparing to intercept. That they were prepared to take their own lives and other's lives. The danger faced would be immeasurable ... To summarize my thoughts at the time: we were possibly about to face subjects who had training and had attempted to commit atrocities on innocent human beings with complete disregard for their own lives. They had prepared devices in order to achieve this. There was a real tangible danger that if we didn't act quickly, correctly there would be an extreme loss of life - how would you feel??? What would you do??"

The time it took to complete these briefings meant that the firearms team was not deployed until 9:27, when they got in their cars to make their way to the address. This delay led the surveillance teams to complain that they did not have the necessary support to stop all the individual residents 
who were leaving the address. Furthermore, although they were issued their own Glock pistols, these were to be used for personal protection only. After positive identification, they were not to challenge the suspect Hussain Osman (codename "Nettle Tip"). Their job, they had been told, was to "contain" any suspects leaving the premises - a metaphorical expression their supervisor did not specify, even on request. The expression had come from Commander McDowall, who had meant that although the surveillance officers were not supposed to make the stop, they had to metaphorically contain the threat posed by the suspect at the residence and prohibit it from spreading further.

\section{Episode 1: The "Positive" Identification}

At 9:33, Jean Charles De Menezes (JCM) left the communal entrance at Scotia Road on his way to fix a broken fire alarm in North London. A red surveillance team officer known as 'Frank' in a van parked nearby was the first to see him. Frank had a handheld video recorder with him but was unable to take any film of JCM since - as he explained to the other members of his team he was at that moment "relieving" himself into a milk bottle. But he communicated over a closed circuit radio to his team members that JCM was "worth a second look", thus framing JCM as a possible target. 'Edward', also of the red team, was parked in a car park opposite, and he described the approaching JCM as "North African". As JCM moved away from Scotia Road, the grey surveillance team took over from the red team. 'Harry', one of the grey team officers, followed JCM on foot and noticed that he was looking over his shoulder, describing him over the radio to his colleagues as "acting in a wary manner and appearing nervous". Two other officers, 'James' and 'Ken', drove past JCM in a car, and both only saw a partial glimpse of his face. Whilst sitting in the car James took the opportunity to look at the photograph of Nettle Tip and concluded that JCM was "possibly identical with" the suspect and was in effect "a good possible likeness". He recorded this in his $\log$ (evidence D459) and at 9:41, James contacted Pat, the surveillance monitor in the Scotland Yard control room. Pat's log has an entry stating that an as yet unidentified male was "possibly identical with" the suspect.

However, because JCM was still not identified, Commander Dick and other officers in the control room wanted to know whether there was enough ground for a positive identification. James was called on his mobile and at 9:46 one of the logs in the control room states that the "not identified male was discounted" and that "surveillance teams [had] to withdraw to [their] 
original positions". As a result, the decision was taken to deploy an arrest team (SO12), and not the firearms team (SO19), to conduct a stop of this unidentified male for the purpose of intelligence gathering.

In the meantime, JCM had got on a bus at Tulse Hill and was shadowed by 'Ivor', another member of the grey surveillance team. Ivor sat in the disabled seating area in the front of the bus with JCM a few rows behind him. At 9:43 Harry telephoned Ivor, who told him that although he had not been able to identify the subject as Nettle Tip, he did say that he had "distinctive eyes" and was "Mongolian" looking. In the evidence that he gave to the inquest (transcript from October 22), Ivor explained his comments as follows:

“... his description was fairly bland. As I have said in the statement, he's about 5-foot 10, proportionate athletic build with short dark hair and he had some stubble. But what I noticed [as] particularly striking was his eyes. What I mean by that is that the eyes appeared not quite but almost oriental in appearance ... [meaning] almond-shaped" (October 22 transcript, p. 148).

Based on this telephone conversation, Harry then confirmed over the closed circuit radio that Ivor could not confirm that he was Nettle Tip. At 9:47 JCM got off the bus at Brixton Road followed by Ivor. JCM walked towards the entrance of the Brixton underground station, but saw a notice saying that it was closed for security reasons. He then returned to the bus stop. Ivor and other surveillance officers transmitted this to James. At 9:49, JCM got back on the bus. James contacted Pat in the control room because he wanted to make sure that they had heard about JCM's movements as he thought they looked suspicious and might be an anti-surveillance tactic. Pat then relayed to Commander Dick and her team that JCM acted "nervous and twitchy".

When JCM has got back on the bus, Commander Dick told Pat to order the surveillance team to continue. She also instructed Pat to ask James to "tell them a percentage of identification", in other words, put a percentage on how sure they were that the man they were following was Nettle Tip. James, however, responded on the basis of his professional expertise that he thought it was a ridiculous question; he felt that identification was either fully positive or negative ("he is or he isn't" as he put it) (evidence D459), but he nonetheless asked around his team over the radio. Because no one replied he took it that none could assist in a positive identification. Pat then asked James if he could say anything at all to help answer the question and to assist the 
Commander in her decision-making. Pressed for an answer, James replied, "for what it's worth, I think it's him". Upon hearing the reply, Pat communicated to Commander Dick and her command team "It is him, the man off [the] bus. They think it is him and he is very, very jumpy". On the basis of the positive identification, Commander Dick decided to mobilize the firearms team to make the stop.

Communication. Figurative language created and reinforced the frame of a positive identification. In the control room, Commander Dick was initially aware that JCM was not directly identified, following the standard binary identification protocol which suggests that a suspect is either directly positively identified (either confirmed or discounted in case it is not the suspect) or not. At the same time, she had been hearing words and expressions that framed JCM as "a good possible likeness", "possibly identical with", as acting "nervous and twitchy" and as suspicious in his movements. All these expressions established the possibility that JCM, in terms of his profile, might be Nettle Tip. Caught between these competing frames - i.e., unidentified versus a "matching" profile - Commander Dick iterated between these frames with her question "for a percentage of identification" (see also Table 1). The question suggests a scalar image of identified physical similarity (or lack thereof) as an assessment of the probability that JCM is the suspect. The image appears discursively motivated by the historical connection between the lexicon of physical similarity ("possibly identical with", "a good possible likeness") and that of probability or likelihood. Sweetser (1990: 46) refers to this as the like-likely link, suggesting that conceptually we often connect an assessment of physical resemblance to an assessment of probability (in actions and outcomes). The image itself is based on addition, with the level of certainty about the identification rising with a higher percentage.

The "percentage identification" question subsequently primed James, the senior surveillance officer, in his response. Whilst initially rejecting the question in favor or the binary classification system, he then said; "for what it's worth, I think it's him". The idiomatic expression of "for what it's worth" by James captures his ambivalence towards the question but also implies an addition that coherently connects with the scalar image. The use of the word "jumpy" by Pat in turn may have come from the earlier assessment of JCM acting suspiciously and being nervous, but is much stronger in its confirmation of the suspect and the impending danger. Throughout all of the accounts that Commander Dick has given, both written and verbal, to the inquest she refers to how she was "building a picture" (e.g., October 6 transcript, p. 75). She clearly aimed 
for cognitive closure and tried to align various verbal words and expressions, and the meanings that these evoked, into a single "frame". The result however is that with her intervention authority trumped a deference to expertise and the importance of founding the identification solely on direct and immediate observations on the ground (Weick et al., 1999; Whiteman and Cooper, 2011).

Emotions. The vocabulary reported above suggests both that the team was intent on inferring the emotional state of JCM based on the behavior they perceived, and that the emotional terminology they employed to characterize JCM increased an overall degree of nervousness or anxiety about the suspect. In particular, Commander Dick seemed to respond to the expressed emotions of officers around her, who urged her to make a decision. Pat expressed increased agitation when he relayed the information from the surveillance officers, and this placed pressure on her to follow suit. Pat's emotional expression of JCM being first "nervous and twitchy", amplified into "very, very jumpy", which suggests that the suspect was nervous and potentially on the verge of reaching his target for the detonation of a bomb. As Commander Dick later on testified at the inquest, her sensemaking was strongly guided by the emotional arousal that came across in the chain of communication, and which she claims was reinforced and strengthened across the interactions that she had with officers in the control room:

"I already knew that he was nervous. I am sorry the word that Mr Cremin [in the control room] wrote down was: 'he is very, very jumpy'. I had asked what he was carrying, I subsequently was told that he was nervous, and I think the phrase 'agitated' was used, so at this stage I am building a picture ... I think I should also add, I never got an answer to the specific question of what is the percentage or what is the 1 to 10 , but Pat again said at that stage, 'They think it's him', and he said it with some urgency, 'They think it's him', so you know, my level of confidence has gone up again twice, two more notches because of that." (October 6 transcript, pp. 149 and 151).

"Pat said 'They think it's him' twice and the second time he said it, he said it with some urgency, as we are getting towards the tube station, Pat said, when I got no [direct] reply to the percentage question, he said 'They think it's him' with a certain amount of emphasis and urgency." (October 8 transcript, p. 22). 
Materiality. The commitment to the frame of a positive identification is also closely linked with perceived material cues. This is evident in how the picture of the suspect was used in comparison with the profile of Nettle Tip. This image, as a material object, afforded certain comparisons and thus also certain interpretations of whether JCM was like Nettle Tip or not. Entries in the surveillance log indicate that JCM was variously described as having "fair skin" (evidence D456), a "light skinned African male" (evidence D459) with "stubble" (D456), which could imply that the suspect on the picture may have shaved off his beard. Besides aiding in the identification, the picture that surveillance officers had to rely on also anchored their perceptions

of JCM. Another type of key instance of material anchoring was the movement of JCM away from Brixton station. While it could have been interpreted otherwise, in this context this movement was perceived as an anti-surveillance tactic, a selective projection or perception that only made sense in the context of the surveillance operation and of the earlier verbal framings of him as potentially the suspect (as acting "nervous and twitchy" and being "jumpy").

\section{Episode 2: The Chase to Stop the Suspect}

On the basis of the positive identification, Commander Dick decided to mobilize the firearms team. Trojan 84, tactical adviser to the firearms team, was told that he needed to get "in contention" with the bus. DCI Purser was at the base where the firearms team was stationed and was in direct contact with Trojan 84. When Commander Dick asked him nervously "are you getting this", "are you getting all this?", he cut her short and said, "yes, yes, yes, we are rolling, we are rolling". Five cars with specialist firearms officers then set off to catch up with the bus, with the control car at the rear.

At around 10:01 Commander Dick gave the order that "if he gets off the bus, I want him stopped". There had been some discussion between Commander Dick and others in the control room at this point as to whether the suspect should be allowed "to run". It was recognized that the suspect in the bus was heading towards Stockwell Underground station, and the question was whether he should be allowed to continue into the station. However, all that the firearms officers heard was to "stop" the suspect, which in their mind meant a confirmation of the suspect and the order of a critical headshot, consistent with the briefings that they had received in the morning. At around the same time as the order was given, James transmitted over the Cougar radio which was audible to all including his own surveillance team - that CO19, the firearms team, 
might be making its way through the follow. "All units alert, CO19 coming through". This was meant to warn surveillance officers that firearms officers were being deployed, that they had to make space and secure themselves from being mistaken for a target and that they had to point the firearms officers in the direction of the suspect. The firearms officers, in their five cars, were ordered to "get behind the bus", which was explained as having to "hang back behind the surveillance team behind the bus" to avoid compromising the surveillance operation. The surveillance officers then reported that the suspect was getting off the bus. Trojan 84 thought at that point that he might be behind the wrong bus, and in any event he told the control room that they were not "in contention". Superintendent Johnston, who was in the control room, heard the question being asked on behalf of Commander Dick by Chief Inspector Esposito, who was in contact with the firearms team; "What do you mean you can't do it? Get yourself there".

In the meantime, 'Ken', one of the surveillance officers, saw JCM get off the bus and followed him to Stockwell station. He saw him go in and transmitted this over the Cougar radio. Ken entered the station at 10:02:56 where he saw Ivor, another surveillance officer. Both of them observed JCM collect a copy of the Metro newspaper, get a ticket from his pocket and go towards the entrance barriers to the station. Ivor recorded this instance in the running log for the surveillance team (evidence D467). Ivor, still unsure as to whether JCM was the suspect, then asked over the central Cougar radio; "Do you want him lifted?" Ivor was aware that firearms officers were mobilized and that his own role as part of the strategy was restricted to surveillance. James relayed this to Pat as, "Do you want him detained?" and made it clear that the decision had to be made very quickly. Commander Dick then decided that SO12, special branch officers, who were near the site were to do the stop. Pat believed that he relayed the instruction after a very small delay, but James later said that he never received any response to his question. At 10:02:45, the first cars with the firearms officers arrived at the junction near the underground station. At 10:03, Chief Inspector Esposito in the control room received information from Trojan 84 that they were there, and he relayed that information to Commander Dick, who countermanded her decision that the arrest team (SO12) do the stop and said "SO19 [are] doing [the] stop, do not let surveillance intervene". After Commander Dick had given the countermanding order, Pat recorded that the subject was going down the escalator. At this point, 'Ralph', the team leader of the firearms team, realized that the suspect was making his way to the escalators and possibly already underground. In response, he asked his tactical adviser, Trojan 
84, to confirm whether this meant "state red". The order was confirmed and Ralph called state red over the radio to his firearms team, which was effectively an order for his team to perform an armed intervention.

Communication. The communication between the key officers in this episode included various expressions, of which the discussion around whether JCM should be allowed to "run" played an important role. The expression confirmed the suspect's status and emphasized the need for swift, decisive action to stop him in his tracks. Then the order by Commander Dick to "stop" the suspect had major implications for the interpretations and actions that followed. In particular, the firearms officers interpreted "stop" as a confirmation of JCM as Nettle Tip and in effect as an order to carry out a critical headshot. As C12, for example, later on explained (October 24 transcript, p. 158).

"This was an identified suicide bomber to me. Our orders were we were only going to act or intervene on identified suspects. This person had been identified as a suspect and therefore potentially had equipment with him in order to cause mass destruction, mass death. It was from that information that I had been given and from his actions and what I perceived him to be, getting closer to us in order to give me and my colleagues and the public the full benefit of any potential blast, that is why I came to that conclusion that I had to use force as soon as possible".

Commander Dick, later on in her evidence to the inquest, suggested that she had used various phrases and words (such as "interception, intervention, detain, arrest, stop, challenge") (October 7 transcript, pp. 177 and 188) to describe her decision to others in the control room, but had only communicated the "stop" order directly to the firearms officers.

Emotions. The recorded communications during this episode reveal particular emotions being expressed and amplified in the verbal communication between the commander and the officers on the ground. Commander Dick's communications first express concern and anxiety about the suspect getting away ("are you getting this", "are you getting all this?" and, "yes, yes, yes, we are rolling, we are rolling"). The suggestion slightly later that the firearms team is unable to follow JCM off the bus elicits what appears to be an angry command ("What do you mean you can't do it? Get yourself there"). The authoritative and urgent way in which this order was expressed in turn led the firearms team on the ground to fear that they might be too late to 
contain the threat posed by the suspect, and this further reinforced their commitment to the frame of a chase and the necessity of stopping the suspect in his tracks (transcripts October 24 and 27).

Materiality. These interpretations of chasing a terrorist suicide bomber were reinforced by material cues and observations and the way these observations were communicated. When Commander Dick gave the stop order, JCM was moving towards Stockwell tube station. This station was seen as a potential target destination for an explosion, because it was the same station that three of the failed bombers had entered the day before. This material circumstance on the ground selectively led her to perceive JCM as a possible terrorist bomber, as opposed to reading his movements as the actions of a normal commuter. In the words of Commander Dick (October 7 transcript, pp. 171 and 176):

"... most importantly, although I was not certain that he was a suicide bomber intent, I thought he very well might have been and I did not think it was -- I did not think it was right at all to allow him to go unhindered without any challenge on to a tube train".

"I thought Stockwell tube could be a destination. I didn't think early on: oh dear, I hope he is not going to Stockwell. I thought: he could be going to Dorset Road, he could be going to Stockwell tube and then I thought: Stockwell tube is the same place as yesterday [i.e., the failed bombing attempts of the day before]".

For the firearms team, their physical location behind JCM and their subsequent bodily experiences of racing through London and running into Stockwell station grounded the framed scenario of a chase or pursuit, regardless of the fact that JCM himself was not actually running. This material anchoring, in other words, strengthened the conceptual frame of a chase or pursuit,, and, as a result, the firearms officers genuinely believed that they were in pursuit of a running suspect who was getting away. C12, for example, described his experience as follows (October 27 transcript, p. 68):

"I remember distinctly running down the escalators and there are two things I remember. Because on escalators they start off very -- the heights are different, and as I sprinted down them, I nearly fell over, because of the different heights; and I was just so keen to get there, because I knew we had the time delay; and all I had going through my mind was: I have got to get to him, I have got to get to him, I have got to get to him before he goes, and I distinctly remember that". 
Whilst the material anchoring of verbally produced conceptual frames may strengthen the commitment towards a frame, perceived cues may also violate a frame and as such provide the basis for a reframing of the scenario. Interestingly, when JCM arrived at Stockwell tube station, Ivor saw him collect a copy of the Metro newspaper, a cue that in his perception did not square with the scenario of a suicide terrorist who is about to detonate a bomb. Ivor effectively became doubtful when he perceived a material cue (i.e., the picking up of a Metro newspaper) that violated the framing of JCM as a terrorist bomber. At the inquest he explained his actions as follows (October 22 transcript, pp. 166-167).

"The word I actually used, [just] to clarify, and this is an important point, I understand, the word I used is, 'Do you want this man lifted?'. What I meant by that was to detain and arrest him."

The lifting idiom refers to Ivor being able to pick the suspect up and stop the entire chase from unfolding any further. Ivor's act also shows that perceived cues may challenge the expectations associated with a prior established frame, and it thus highlights the tacit role background information played in the interpretation of the events in front of him.

\section{Episode 3: Containing the Threat}

Both Ken and Ivor from the surveillance team were directly behind JCM on the escalators. About halfway down the escalators they saw JCM begin to run, probably to catch the next train, and turn left at the first archway entrance towards the platform. JCM entered the train carriage doors immediately opposite the cross tunnel, turned right and walked along the carriage to the seat just beyond the next set of double doors facing the platform, where he sat down. Ken entered through the same set of double doors and took a seat on the far side of the carriage facing the platform. Ivor turned right, walked down the platform, and entered the train through the single door beyond where JCM was sitting. He took a seat on the same row of seats as JCM, but a few seats away.

C12, who was one of the first firearms officers to arrive at the underground station, had heard Trojan 84 say something to the effect of, "They said that he was to be stopped getting on the tube, he must not be allowed to get on the tube". Almost immediately afterwards, Ralph had declared state red on the firearms team radio network and C12 sprinted towards the station. When $\mathrm{C} 12$ got to the entrance, he made eye contact with $\mathrm{C} 2$, which was another reassurance to 
him that they were deployed and that other firearms officers were there. C12 then jumped over a ticket barrier, pushing a member of the station staff out of the way, and he drew his pistol. C2 also vaulted over the ticket barriers, where he was challenged by the staff and shouted "armed police, get back". At the bottom of the escalator, C2 and C12 saw 'Malcolm' from the surveillance team, who said to them "on the northbound tube". They went through the cross tunnel archway and saw Ken standing by the open doorway who pointed to the next set of doors on his right. $\mathrm{C} 2$ and $\mathrm{C} 12$ then moved along the platform in that direction. C5 went to the single door at the left-hand end of the carriage, to ensure that he would be on the train when it departed.

Ivor saw $\mathrm{C} 2$ and $\mathrm{C} 12$ coming towards the next set of open double doors and realized that they were firearms officers. Ivor assumed that they were looking for JCM, and so he stood up, walked over to the open double carriage doors, and placed his left foot against the open door to prevent it from shutting (October 22 transcript, pp. 183-184). He leaned partially out of the carriage, shouted, "he's here", and indicated JCM with his right hand. Ivor then turned and saw that JCM had stood up with his hands were slightly in front of him. C12 and C2 interpreted JCM's movement as a direct challenge. Ivor, in a split-second reaction, grabbed JCM by wrapping both of his arms around his torso, pinning his arms to his sides, and pushing him back into the seat where he had previously been sitting.

As Ivor pushed JCM back, C12 moved in virtually on top of Ivor, slightly behind him, pointing his gun past Ivor's head and firing a number of shots. He was aware of C2 to his left. Both men had been trained that a single shot to the base of the skull would cause total incapacity. However, the perceived threat and their position, leaning over Ivor, meant that both fired eleven shots in total. JCM was shot seven times in the head and once in the shoulder at close range, and died at the scene. As the shots were fired, a civilian witness (Anna Dunwoodie) sitting opposite JCM on the train observed his final moments (November 3 transcript, p. 17).

"I remember that his eyes were closed and I remember that he had ... you know, it's a hard thing to try to explain, but his eyes were closed and he looked almost calm, which again I hesitate to say that, but ... I guess he had a gun pressed, and there wasn't very much he could do about it".

Communication. The chain of events in this final episode was determined more by the action on the ground than discussion over the radio. However, Trojan 84's confirmation according to 
which JCM "was to be stopped getting on the tube, he must not be allowed to get on the tube" had a major impact on the firearms team because of its directive modality. Ralph's declaration of "state red" was then the explicit code that the team needed for an armed intervention. Further, the expression "he's here" directly confirmed to the firearms officers that the suspect was there to be acted upon.

Emotions. Reports by the firearms officers confirm that their actions were motivated by strong emotions and suggest that the arousal and reinforcement of emotions in the previous two episodes had a significant impact on their decisions and actions on the ground. While running down the escalators, $\mathrm{C} 2$ and $\mathrm{C} 12$ reported becoming frustrated and agitated, fearing that the suspect had already entered the underground system and had got away. C12 later on described his experience as follows, which illustrates how previous episodes of sensemaking had intensified his emotional state (October 24 transcript, p. 101);

"I remember or I recall thinking that we were going to have to come up against these people with a totally unknown threat, the highest possible threat that certainly I have ever could imagine coming up against. As I have said before, this -- the whole journey, if I can call it that, was an extremely emotional one for me, both at the time of the briefing, listening to the briefing and listening to the nature of the threat and the danger these people posed, and possibly not going home again at the end of the day".

Importantly, this fear - expressed by the other members of the team, too - seemed to have significantly reinforced the need to take decisive action to incapacitate the suspect:

"Fear was certainly present, but as regards controlling my actions, it possibly had some effect, yes. I can't deny that. I felt I was going to die, certainly, and I took action in order to stop that" (C12 in the October 27 transcript, p. 133).

It also seems that the final actions of $\mathrm{C} 12$ and C2 reflected heightened emotions. In fact, knowing full well that one shot to the head would have been sufficient, both fired multiple shots, in an attempt to ensure that the presumed suicide bomber would be definitely incapacitated.

“... the threat was such I couldn't take any chances. I just couldn't do it. I am there to protect the public, and I have there, for all intents and purposes, a suicide bomber, and if I 
don't act and if I don't act immediately, we could all die" (C12 in the October 27 transcript, p. 132).

A similar kind of fear seemed to motivate Ivor to engage in extraordinary action as he grabbed JCM in his arms. He explained it as follows (October 22 transcript, p. 187):

"Assessing that I may be dealing with a terrorist subject, and naturally fearing for the safety of the public on the carriage, the armed officers and myself, I grabbed $\mathrm{Mr}$ de Menezes by wrapping both my arms around his torso, thereby pinning his arms to his side"

Within the space of a few seconds, Ivor had shifted from a frame of suspecting JCM's innocence to impromptu action to defuse the situation. In doing so, he risked his own life, as he could have easily been hit by a stray bullet.

Materiality. In this episode, a number of material cues suggested to the firearms officers that they were deployed and were about to find themselves face-to-face with a terrorist suicide bomber. One such cue was the eye contact that $\mathrm{C} 12$ established with $\mathrm{C} 2$ :

"The eye contact with Charlie 2 was of immense importance to me at the time because I didn't know where the other firearms officers were. All my knowledge at that time was that we were the only vehicle there ready to respond. So when I saw Charlie 2 at the entranceway it was certainly a reassuring thing that another firearms officer was there" (October 24 transcript, p. 133).

Meanwhile, Ivor appears to have interpreted the situation differently. He initially followed standard protocol by pointing to the suspect, but he then took the unprecedented step of bear hugging the suspect and pushing him back into his seat. As a surveillance officer he should have confined his role to clearing the way for an armed intervention. Instead, he chose to physically detain the suspect, as an alternative to an armed intervention and to allow more time for a positive identification. Ivor later on described his sensemaking at the time as follows (October 23 transcript, pp. 188 and 207):

"When I saw the CO19 officers on the platform, I could only assess that the intelligence picture had changed, and prior to me coming into the station, we were dealing with a man 
possibly identical with somebody who had been involved in an attack the day before, and I could not rule out that he may be carrying arms or explosives. That was the basis of my concern..."

"...he was possibly identical with Nettle Tip, but he may have been an associate from the same address, and therefore it would have been a possible option to continue surveillance of him with a view to him leading us to other members of the team or premises associated with it...".

$\mathrm{C} 2$ and $\mathrm{C} 12$, however, understood Ivor's act to be a response to an aggressive move by JCM. When $\mathrm{C} 12$ arrived in the train carriage he saw JCM advancing towards him and felt that the blue denim jacket he was wearing appeared "bulky" (October 24 transcript, p. 152), suggesting to him that an explosive device could be concealed under his clothing. He also interpreted JCM's move as a physical act of aggression:

"...it was his continued movement towards me, that I thought this is almost like the point of no return, this is it now, something is going to happen" (October 27 transcript, p. 139).

"I thought, 'He's going to detonate. He's going to kill us'. I had no alternative. I must shoot him before he kills. In my mind I had no choice” (October 24 transcript, p. 156)

C12 was not able to interpret JCM's movements as simply the natural inclination a person has to stand when pointed out, especially when men with guns were advancing towards him. It also transpired later on that the jacket was an ordinary denim jacket and had not been zipped. Whilst C12 was perceptually alert to cues in his surroundings, he interpreted these in a way that was, conceptually, driven by the already established framed interpretation of JCM as a suicide bomber. This also meant that cues or prompts, such as the acts of Ivor, were not responded to in real time.

\section{DISCUSSION: A MODEL OF COMMITTED SENSEMAKING UNDER PRESSURE}

Our analysis demonstrates how communicative, emotional and material factors together led to an increasing commitment to framing JCM as a terrorist suicide bomber. In this section, we propose a theory about the key processes at play, present an integrated model (Figure 3), and then detail the implications of our analysis for sensemaking research in general. 
Insert Figure 3 about here

\section{Communicative Grounding}

Communicative grounding refers to the stock of shared presumptions that are established in ongoing communication, as common ground, and which in turn fuels inferences in a pragmatic and goal-directed manner (Clark, 2006; Grice, 1989). Thus, common ground involves knowledge common to a group of individuals, as well as the additional, recursive notion that the participants are aware that they share the knowledge they share (Clark and Marshall, 1981). In our case, individual officers did not automatically know what the others knew and what others deemed to be the appropriate course of action, as part of their coordinated activity. Hence, they had to build up common ground between them, one consequence of which was that their ongoing sensegiving and sensemaking was subsequently channeled into a particular direction.

This overall process involves three important sub-processes (see Figure 3). First of all, the process of communicative grounding essentially implies a sequential organization, because acts of sensemaking and sensegiving are contingent on preceding contributions to the dialogue (Sacks et al., 1974). As such, earlier acts of sensegiving, as instances of linguistic framing (see Figure 3), place a strong claim on how individuals, as part of a collective, subsequently and cognitively make sense of their circumstances. Second, the initial provisional frame that is established through sensegiving is likely to be repeated and reinforced in the course of communication in a contingent way. That is, current instances of communication connect with past instances of sensegiving and sensemaking but also fuel inferences for future sensegiving and sensemaking in a certain direction. Third, the collective nature of the process, and the involvement of individuals in it, has the effect that it binds the actors to the shared frame that has been built up. As such, it provides a strong relational bond among a collective to the shared presumptions that have been established.

Thus, acts of sensegiving and sensemaking around specific frames accumulate, or stack up, in the course of ongoing communication (Clark, 2006). They build on each other, which also means that earlier instances of sensegiving, and thus earlier cognitive frames "settle" as part of the ongoing communication, something that was aptly demonstrated with the language used for profile matching (e.g., expressions such as "good possible likeness" and "identical with") in the 
identification of JCM (see also Table 1 for details on this process). The result of this process is that a joint commitment towards a framing and course of action further on in the process - e.g., Commander Dick's decision to mobilize the firearms team - generally have to be discharged to honor earlier commitments - e.g., the early sightings of JCM matching him to the profile of Nettle Tip. This generally demonstrates that the very process of collectively building up common ground makes it particularly hard to suspend or abort an agreed-upon course of action later on in the process.

\section{Emotional Contagion}

Our analysis generally demonstrates how aroused and expressed emotions impact sensemaking. We also specifically observed across the three episodes in our case a spreading and heightening of the same emotions over time. We believe that these particular observations point to a process of emotional contagion where actors influence each other through expressed emotions and to such an extent that the collective comes to share the same emotional state. Our case provides a number of specific examples of how individual police officers took note of each other's emotions and adjusted their own emotions accordingly (Hatfield et al., 1994; Pugh, 2001). In groups emotions may spread in this manner and create a "ripple effect" (Barsade, 2002); emotions are transferred across actors and come to consume the entire collective and their subsequent sensemaking. This overall process involves three sub-processes (Figure 1).

First, it starts with the arousal of either positive or negative emotions. Negative emotions are more conducive to being transmitted than positive ones (Barsade, 2002). The arousal of such emotions through embodied acts or communication to one another creates an 'implicit affect' (cf. Barsade, Ramarajan and Westen, 2009) that when picked up, primes and reinforces the same emotion in others, as happened in our case in the identification of JCM and the need to contain the presumed threat that JCM posed.

Second, the energy level expressed in articulating emotions to others, either positive or negative, is positively correlated with the strength of its subsequent spread and valence (cf. Barsade, 2002). This is evidenced in the data, where the emotional expressions appear to have been more moderate in the beginning but increase in strength or intensity when repeated. A crucial escalation of this kind took place at the end of the first episode when Commander Dick presses James to give a "percentage of identification", and James responds, "for what it's worth, it's 
him". This was picked up by Pat who communicated that "It is him, the man off [the] bus. They think it is him and he is very, very jumpy." The underlying mechanism for this contagion process is the inherent propensity of human beings to mimic each other's behavior, emotional expressions among them (Hatfield, Cacioppo, and Rapson, 1992). Such mimicry is followed by the conscious or unconscious adjustment of one's own mood against the expressed emotions of others (Barsade, 2002).

Third, analogous to the process of communicative grounding, the repetition and reinforcement of similar emotions between actors leads to the spreading and heightening of emotions into a shared emotional state. The episode leading to the positive identification suggests that as a result of emotional contagion Commander Dick, Pat and others in the control room all came to share a degree of nervousness and anxiety about the possibility of JCM being Nettle Tip. Furthermore, the increasing commitment, through reinforcement and repetition, to the same emotions created in turn a joint emotional state of nervousness and fear among virtually all of the police officers involved in the operation.

Both the processes of communicative grounding and emotional contagion interacted in our case study, and as such, amplified the commitment to framing JCM as a suicide bomber. Both processes, as highlighted in Figure 3, were also directly linked with material anchoring.

\section{Material Anchoring}

Material anchoring underscores the role that materiality plays in anchoring thoughts or emotions. Our analysis highlights three types of materiality: the material circumstances in which the actors found themselves at various points (e.g., locations such as the metro station), their physical demonstrations and gestures (e.g., behavior, movements or positions), and the material objects that they had at their disposal (e.g., guns, hollow point bullets and video and film equipment). Critical to understanding the commitment to the framing of JCM as a terrorist suicide bomber that had to be stopped is, we suggest, a correspondence between a conceptualization, established through framing language and expressed emotions, and perceived material cues. Such a correspondence, as a direct anchoring of the frame, strengthens the commitment to the interpretations and inferences afforded by a framed conceptualization (Hutchins, 2005).

As our case illustrates, material cues, gestures and objects mediate sensemaking and this also explains why the overall process became less expert-driven (Whiteman and Cooper, 2011) and 
more cognitively closed in the sense that a provisional and possible version of events was in a material sense objectified as the most likely state of affairs. As a result, the sensemaking of police officers became driven by beliefs and presuppositions, rather than their expertise or even reflective thought. As an exception, Ivor was able to withstand the pressures of communicative grounding and emotional contagion and the blind commitment of everyone else towards the framing of JCM as Nettle Tip. His sensemaking and sensegiving remained expert-driven, but just like Wagner Dodge in the infamous Mann Gulch fire (Whiteman and Cooper, 2011), he was not able to make the others follow his sensegiving. The reason for this is twofold. First, Ivor was the person who during the entire operation remained the closest of everyone to JCM and as such he channels his sensemaking and sensegiving towards others, rather than being on the receiving end of others' sensegiving tactics, including their expressed emotions and any associated pressures that they place on him. As such, he had a degree of control over his own framing and sensemaking of JCM, and was not unduly influenced by the acts of sensegiving or expressed emotions of others. Second, the material cues that Ivor perceived, including the fact that JCM picked up a copy of a Metro newspaper when he entered Stockwell tube station, did not anchor or even afford a probable interpretation of JCM as a suicide bomber. As such, he was not caught in the double bind that the other police officers found themselves in, where verbal expressions, emotions and perceived material cues aligned and thus strengthened the fidelity of framing JCM as Nettle Tip.

\section{THEORETICAL CONTRIBUTIONS AND IMPLICATIONS}

Our findings shed light on how commitment builds up and escalates in sensemaking under pressure. Our analysis theoretically specifies the process of commitment building that Weick (1988, 1993b) initially described in figurative terms as an 'enacted environment'. Prior acts of framing established in earlier episodes of communication provide the source for future expectations and for subsequent episodes of communication (Weick, 1988, 1993b). In subsequent papers (Weick et al., 2005) Weick described the process again in avowedly linguistic terms when he defines sensemaking and environmental enactment more generally as an act of turning circumstances "into a situation that is comprehended explicitly in words and that serves as a springboard to action" (Taylor and Van Every, 2000: 40, Weick et al., 2005: 409). Yet, it is fair to say that in these later accounts words and vocabularies are seen to simply cue, as labels, 
salient cognitive frames (Weick, 1995; Weick et al., 2005) but do not themselves actively help shape or construct meaning.

Our results extend previous work on sensemaking in showing that language has a formative effect on meaning construction, and thus directly impacts behavioral enactments. We have labeled this in our model as linguistic framing, which marks a shift in focus from considering words as priming the activation or accessing of already existing frames and their effects to instances of framing in real-time sensemaking and communication (i.e., the key role that specific natural expressions and improvised utterances such as "a good possible likeness" played in the creation and reinforcement of particular frames as part of ongoing sensemaking).

We also provide an explanation of how an initially constructed framing may escalate from being a provisional interpretation to a collectively held belief that lays a strong claim on future expectations and inferences. We describe in our model a set of communicative processes linguistic framing, reinforcement over time, and joint orientation development - as enabling conditions for a commitment to build up and potentially escalate over time. These processes detail the broad picture described by Weick $(1988,1993 b)$ and provide important implications for our understanding of commitment in sensemaking (Maitlis and Sonenshein, 2010). These processes together describe how an initial provisional framing provides a consciously hypothetical frame or schema for organizing experience and for powering inferences, although over time, and through repeated reinforcement of the same framing, it may evolve into a more naturalized, taken-for-granted joint orientation that renders the established reading of the environment as 'objective' and deflects attention to other readings and interpretations. Besides this 'objectification' of a particular framing, the processes leading up to the joint orientation also bind participants to the collective frame and course of action that has been established, making it very hard to suspend or abort an agreed-upon course of action. Through communication and social interaction, commitments earlier on (say of identifying a civilian as a suspect) settle and seed the next steps, and thus in a way accumulate, or stack up, in the course of ongoing communication. The overall commitment of the collective increases throughout the process, and accordingly joint commitments towards a framing and course of action further on in the process have to be discharged to honor earlier commitments (Clark, 1996). 
This path-dependent nature of this process explains, together with the objectification of a framing, how an overall commitment may escalate (Weick, 1998, 1993a,b), and may blind participants to alternative courses of action. The currency of these explanations is, we believe, underscored by their ability to account for past cases of sensemaking under pressure such as the Mann Gulch fire (Weick, 1993a) and Snook's (2000) study of a friendly fire shooting in Iraq. In both cases, the initial framing of a "10 o'clock fire" and "hits there" had prompted conventional scenarios of routine fire-fighting and of surveillance tactics in a no-fly zone. Subsequent communication and the movements and behaviors of the firefighters and pilots involved also initially reinforced this framing and led to a joint orientation and strong commitment to a particular course of action although afterwards it appeared that in both cases the framing had not tallied with reality.

In addition to analyzing the formative role of language, we extend the sensemaking literature through our focus on emotions and materiality. Our model integrates interactions between verbal communication, expressed and felt emotions and material cues as they lead to a contraction of meaning. Most sensemaking research attends to language, emotions, or materiality separately (Maitlis and Sonenshein, 2010; Weick et al., 2005), although recent research has moved towards incorporating emotions more specifically (Maitlis and Sonenshein, 2010) and to analyzing the way in which material artifacts and cues feature in sensemaking (Stigliani and Ravasi, 2012; Whiteman and Cooper, 2011). However, there are very few accounts, if any, that combine these various sources and processes of sensemaking into an integrative picture. This is unfortunate in light of the repeated calls for research that takes such steps (e.g., Maitlis and Sonenshein, 2010; Porac et al., 2011; Weick, 2010; Weick et al., 2005)

We have responded to this call. In particular, we have foregrounded the role of emotions, following recent calls for research that incorporates emotions into organizational sensemaking (Maitlis and Sonenshein, 2010; Weick et al., 2005). The limited work that exists (Bartunek et al., 2006; Myers, 2007; Sonenshein, 2009) largely focuses on the arousal of negative emotions such as fear and anxiety at the individual level. With our study we demonstrate how emotions may be identified and analyzed based on text and language based records (compared to recorded audiovisual data) and extend prior work by demonstrating how emotions may spread across individuals, and lead to a joint emotional state. The key insights associated with this process are the way in which emotions may be expressed and cued to others, through gestures and verbal 
expressions. We also theorize how in turn when such gestures and expressions are reinforced and reciprocated by others, they may lead to a heightening of the felt and experienced emotions of everyone involved, and to a joint emotional state of say, fear or panic. The process is partly a conscious one with individuals being aware of the emotions they express to others. Yet, it is also an unconscious or automatic process - as such we use the term contagion - with the spread and heightening of emotions into a joint emotional state based on visceral and embodied reactions of individuals to one another. It may well be, based on comparable cases of organizational change (Huy, 2002: Walsh and Bartunek, 2011), that such heightened emotions may be tempered through specific practices of "emotion management" (Huy, 2002) where managers or superiors acknowledge emotions but calm everyone down at the same time. Yet, like commitment, heightened emotions may act like a double-edged sword; their heightened state in fact facilitates directed and coordinated collective action, whereas more weakly aroused or activated emotions may lead to "inertia" and little action (Huy, 2002). In our case study, this paradox was evident in the lethal and efficient way in which an innocent civilian was shot.

With this description of emotional contagion we advance the limited, individual-level work that exists and emphasize the social contexts and effects of emotions. The three sub-processes of emotional contagion - emotional arousal, contagion (mimicking and reinforcement), and joint emotional state - together also explain previously highlighted outcomes of sensemaking such as panic and fear (Weick, 1993a; Whiteman and Cooper, 2011). We also suggest that this process explanation has broader currency for sensemaking research and may be a lens to explain cases such as the hijacking of United Airlines flight 93 where emotions of fear and panic first had to spread before the passengers were able to mobilize each other into taking coordinated action (Quinn and Worline, 2008).

The process of 'material anchoring' also adds to recent research on materiality and sensemaking. It refers to a correspondence between a conceptualization, established through framing language and expressed emotions, and perceived material cues. Such a correspondence, as a direct anchoring of the frame, strengthens the commitment to the interpretations and inferences afforded by a framed conceptualization (Hutchins, 2005), and as such it leads to a contraction, or stabilization, of meaning. Recent studies (Whiteman and Cooper, 2011; Stigliani and Ravasi, 2012) have largely focused on how material objects and physical demonstrations may afford certain interpretations and inferences. These studies have demonstrated how material objects or 
cues may prompt alternative readings, and may thus engender dynamic and creative inferential thought in the case of expert sensemakers like designers (Stigliani and Ravasi, 2012) or experienced hunters in the arctic (Whiteman and Cooper, 2011). Our analysis, however, suggests that material cues may not only have such generative potential, but can in highly pressurized contexts also lead to a contraction of meaning with individual actors combining material cues with readily available frames.

To illustrate this point, we to return to Whiteman and Cooper (2011) who compare the ways in which an experienced hunter in the arctic and firefighters in Mann Gulch made sense of the material cues that they observed. They argue that greater experience and expertise of particular landscapes or material environments generally leads to more resilient sensemaking in that individuals can infer alternative frames or causal models on the basis of observed cues, and can switch flexibly between alternative readings of those cues as a basis for improvised actions. The crew of firefighters in Mann Gulch, however, lacked the relevant experience of the topography of Mann Gulch and relied on the initial framing of Mann Gulch as a routine fire. We extend the analysis of Whiteman and Cooper (2011) by suggesting that social processes of sensemaking may through their commitments direct how material cues are read, potentially trumping the individual expertise and experience that may exist at the individual level on the ground. An illustration from our data is the offer by Ivor to intervene and detain the suspect, which is not responded to by his seniors who consider the arrival of the firearms officers as materially anchoring the next step in the pursuit of the suspect. Further research could explore in more detail how either sensemaking based on material affordances is influenced by individual experience and expertise as well as by collective beliefs and expectations. Such research could also go further in distinguishing and elaborating on the specific roles of various aspects of materiality such as material surroundings, bodily gestures and specific artifacts - and even their performative or 'agentic' role in these processes (Leonardi and Barley, 2010; Orlikowski, 2007). In our study, we found that the gesturing of an individual cues intentions and an emotional state to others, and that when synchronized with speech (McNeill, 2005) it reinforced the commitment to a frame. Yet, in line with Whiteman and Cooper (2011), further research may focus more specifically on gestures and usefully tease out the interaction between gestures and speech in various scenarios and their impact on individual and collective sensemaking (see also Cornelissen et al., 2012). 
By integrating analyses on communication, emotions and materiality in our model, we also highlight how the interactions between these sources and processes of sensemaking guide and constrain the cognitive frames, or conceptualizations, that are constructed and become increasingly established across time. When we see these sources as signals, we can understand how they might mutually reinforce each other and lead to a stronger belief in a frame and in turn to a contraction of meaning. Likewise, if signals contradict each other it harbors the potential for a re-reading of signals and cues, where individuals alternate between alternative cognitive framings as Ivor did in our case.

Analyses that focus on language, emotions or materiality in isolation may be seriously limited, failing to recognize the nature of sensemaking individuals as embodied agents (Maitlis and Sonenshein, 2010; Whiteman and Cooper, 2011). One of the main insights that emerges from our study is that the bodily actions and experiences of individuals, including their verbal speech and gestures to each other, do not simply express previously formed mental concepts or broader cognitive frames but are part and parcel of the very activity in which concepts and conceptualizations of their environment are actively formed or constructed in real-time. There is therefore value in looking at sensemaking agents 'in the round' and considering their embodied experiences and actions in full. Such integration provides a much better sense of why meaning settles, or contracts around one specific cognitive framing, as opposed to alternative conceptualizations. By considering the interplay between these sources of sensemaking analyses, we will be better able to understand how and why individuals act mindfully or engage in adaptive sensemaking where they update or revise their framing as opposed to collectively and steadfastly holding onto a single, and possibly erroneous, frame (Maitlis and Sonenshein, 2010; Weick et al., 1999; Weick and Sutcliffe 2007: 58).

\section{Limitations and Boundary Conditions}

Although our findings extend prior research on sensemaking under pressure, our study is limited in a number of respects. We collected and analyzed data in relation to a single organization and operation. We cannot claim that the intricacies of this organization and operation directly extend to other organizations. However, the findings can be used for "naturalistic generalization", whereby one recognizes similarities between the findings of the research and the induced theoretical model and that of other cases without making any statistical inference (Stake 1995). 
For example, the impact of episodes of communication on subsequent commitments to a particular framed interpretation at the collective level offers clear parallels with other cases (Weick 1993; Snook 2000). Our findings are also tied to our abductive and sensemaking-based analysis of the data. In contrast, an in-depth psychological or sociological analysis of the same case may lead to different but complementary insights. The case itself also relates to very dramatic circumstances, and the detailed process of communication, emotional contagion and material anchoring may not always have such a significant and dramatic impact on organizational actions as it did in the case examined here. Conceivably, in a less stressful and fast-paced environment, individuals may be able to deliberate or even try alternative courses of action (Cooren 2004).

In relation to our case, a final question worth asking relates to the flipside of commitment in sensemaking. A strong commitment to the common interpretation that JCM was a suicide bomber allowed the firearms officers to carry out their task with lethal consequences and with great efficiency, given the circumstances. But it did not provide them with enough 'requisite variety' to see the cues and the situation they were about to confront as potentially different from what they believed them to be. Whilst Commander Dick in her own mind may have been thinking about "lots of hypotheticals" (October 7 transcript, p. 104) she did not directly communicate her provisional attitude, and the range of possible inferences that this would allow for, to the firearms officers on the ground. As a result, her thinking was not "scaled up" (Weick and Roberts 1993) or "trans-localized" (Cooren 2004; Quinn and Dutton 2005) to the collective level. In retrospect, one could argue that had she communicated her provisional attitude in an unambiguous way, it would have allowed for new emergent inferences to be worked out by individuals. But even so, her actions may not have been acted upon by the individual firearms officers who were repeatedly primed and told to believe that they were coming face-to-face with a terrorist suicide bomber with an absolute disregard for human life. As such, they were put, according to their tactical adviser (Trojan 84), in an "impossible situation" (October 16 transcript, p. 50). We therefore also hope that our analysis and explanations shed additional light on how this unfortunate tragedy was able to come about. 


\section{REFERENCES}

Alvesson, M., and Kärreman, D. (2007). 'Constructing mystery: Empirical matters in theory development'. Academy of Management Review, 32, 1265-1281.

Barsade, S.G. (2002). 'The Ripple Effect: Emotional Contagion and Its Influence on Group Behavior'. Administrative Science Quarterly, 47, 644-675.

Barsade, S.G., Ramarajan, L. and Westin, D. (2009). 'Implicit affect in organizations'. Research in Organizational Behavior, 29, 135-162.

Bartunek, J., Rousseau, D. M., Rudolph, J. and DePalma, J. (2006). 'On the receiving end: sensemaking, emotion, and assessments of an organizational change initiated by others'. Journal of Applied Behavioral Science, 42, 182-206.

Bechky, B.A. (2003). 'Sharing meaning across occupational communities: The transformation of knowledge on a production floor'. Organization Science, 14, 312-330.

Bechky, B.A., and Okhuysen, G.A. (2011). 'Expecting the unexpected?: How SWAT officers and film crews handle surprises'. Academy of Management Journal, 239-261.

Benford, R.D., and Snow, D.A. (2000). 'Framing processes and social movements: An overview and assessment'. Annual Review of Sociology, 26, 611-639.

Brown, A. D. (2003). 'Authoritative sensemaking in a public inquiry report'. Organization Studies, 25, 95-112.

Brown, A. D. (2005). 'Making sense of the collapse of Barings Bank'. Human Relations, 58, 1579-604.

Christianson, M., Farkas, M., Sutcliffe, K.M., and Weick, K.E. (2009). 'Learning through rare events: Significant interruptions at the Baltimore and Ohio Railroad museum'. Organization Science, 20, 846-860.

Clark, H. H. (2006). 'Social actions, social commitments'. In N. J. Enfield, S. C. Levinson (eds.), Roots of human sociality: Culture, cognition, and human interaction. Berg Press, Oxford, UK.

Clark, H. H., and Marshall, C.R. (1981). 'Definite reference and mutual knowledge'. In A. K. Joshi, B. Webber, I. Sag (eds.), Elements of discourse understanding. Cambridge University Press, Cambridge, UK.

Cooren, F. (2004). 'The communicative achievement of collective minding: Analysis of board meeting excerpts'. Management Communication Quarterly, 17, 517-551.

Corley, K.G., and Gioia, D.A. (2004). 'Identity ambiguity and change in the wake of a corporate spin-off’. Administrative Science Quarterly, 49, 173-208.

Cornelissen, J.P. (2012). 'Sensemaking under pressure: The Influence of professional roles and social accountability on the creation of sense', Organization Science, 23, 118-137.

Cornelissen, J., Clarke, J. and Cienki, A. (2012), Sensegiving in entrepreneurial contexts: The use of metaphors in speech and gesture to gain and sustain support for novel ventures.

International Small Business Journal, 30(3), 213-241. 
Cornelissen, J. P. and Clarke, J.S. (2010). 'Imagining and rationalizing opportunities: Inductive reasoning, and the creation and justification of new ventures'. Academy of Management Review, 35, 539-557.

Durand, R. and Vaara, E. 2009. Causation, counterfactuals and competitive advantage, Strategic Management Journal, 30, 1245-1264.

Faraj, S. and Xiao, Y. (2006). 'Coordination in fast-response organizations'. Management Science, 52, 1155-1169.

Fairclough, N. 2005. Discourse analysis in organization studies: The case for critical realism. Organization Studies, 26, 915-939.

Flyvberg, B. (2006). 'Five misunderstandings about case study research'. Qualitative Inquiry, 12, 219-245.

Gephart, R.P. (1993). 'The textual approach: risk and blame in disaster sensemaking'. Academy of Management Journal, 36, 1465-1514.

Gephart, R. P. (1997). 'Hazardous measures: An interpretive textual analysis of quantitative sensemaking during crises'. Journal of Organizational Behavior, 18, 559-582

Gioia, D.A., and Chittipeddi, K. (1991). 'Sensemaking and sensegiving in strategic change initiation'. Strategic Management Journal, 12, 433-448.

Gioia, D.A., and Poole, P.P. (1984). 'Scripts in organizational behavior'. Academy of Management Review, 9, 449-459.

Gioia, D.A., Thomas, J.B., Clark, S.M., and Chittipeddi, K. (1994). 'Symbolism and strategic change in academia: The dynamics of sensemaking and influence'. Organization Science, 5, 363-383.

Goffman, E. (1974). Frame analysis: An Essay on the Organization of Experience. Boston: North Eastern University Press.

Goffman, E. (1981). Forms of talk. University of Pennsylvania Press.

Grice, P. (1989). Studies in the Way of Words. Harvard University Press, Cambridge, MA.

Hare, A.J., and Roberts, K.H. (2010) 'Applying High Reliability Organization Theory to Crisis/Hostage Negotiation'. In E. Rogan and F. Lanceley (Eds.) Contemporary Theory, Research, and Practice in Crisis/Hostage Negotiation. Cresgill, N.J: Hampton Press.

Hatfield, E., J. Cacioppo, and R. L. Rapson (1992), 'Primitive emotional contagion'. In M. S. Clark (ed.), Review of Personality and Social Psychology: Emotion and Social Behavior, 1 4: 151-177. Newbury Park, CA: Sage.

Hatfield, E., J. Cacioppo, and R. L. Rapson (1994). Emotional Contagion. Cambridge: Cambridge University Press.

Hutchins, E. (2005). 'Material anchors for conceptual blends'. Journal of Pragmatics, 37, 155577.

Huy, Q. (2002), Emotional balancing of organizational continuity and radical change: The contribution of middle managers. Administrative Science Quarterly, 47: 31-69. 
Ketokivi, M. and Mantere, S. (2010). 'Two Strategies for Inductive Reasoning in Organizational Research'. Academy of Management Review 35, 315-333.

Lakoff, G. (1987). Women, Fire, and Dangerous Things: What Categories Reveal about the Mind. Chicago: University of Chicago Press.

Langley, A. (1999). 'Strategies for theorizing from process data'. Academy of Management Review 24, 691-710.

Leonardi, P. M., and Barley, S. R. 2010. What's under construction here? Social action, materiality and power in constructivist studies of technology and organizing. Academy of Management Annals, 4, 1-51.

Lerner, J. S., and Tetlock, P.E. (1999). 'Accounting for the effects of accountability'. Psychological Bulletin, 125(2), 255-275.

Liu, F. and Maitlis, S. (2013). 'Emotional dynamics and strategizing processes: A study of strategic conversations in top team meetings'. Journal of Management Studies, forthcoming.

Locke, K., Golden-Biddle, K., and Feldman, M.S. (2008). 'Making doubt generative: Rethinking the role of doubt in the research process'. Organization Science 19, 907-918.

Maitlis, S. (2005). 'The social processes of organizational sensemaking'. Academy of Management Journal 48, 21-49.

Maitlis, S. and Lawrence, T. (2007). 'Triggers and enablers of sensegiving in organizations'. Academy of Management Journal, 50, 57-84.

Maitlis, S. and Sonenshein, S. (2010). 'Sensemaking in crisis and change: Inspiration and insights from Weick (1988)'. Journal of Management Studies 47, 551-580.

Mantere, S. and Ketokivi, M. (2013). 'Reasoning in Organization Science'. Academy of Management Review, 38: 70-89.

Mantere, S., Schildt, H. and Sillince, J.A.A. (2012). 'Reversal of Strategic Change'. Academy of Management Journal, 55, 172-196.

Martin, J., Knopoff, K., and Beckman, C. (1998). 'An alternative to bureaucratic impersonality and emotional labour: Bounded emotionality at the Bodyshop'. Administrative Science Quarterly, 43, 429-469.

McNeill, D. (2005), Gesture and Thought. Chicago: University of Chicago Press.

Myers, P. (2007). 'Sexed up intelligence or irresponsible reporting? The interplay of virtual communication and emotion in dispute sensemaking'. Human Relations, 60, 609-36.

Neumann, R. and Strack, F. (2000). 'Mood contagion: The automatic transfer of mood between persons'. Journal of Personality and Social Psychology, 79, 211-223.

Ocasio, W. (2005). 'The opacity of risk: Language and the culture of safety in NASA's space shuttle program'. In William H. Starbuck and Moshe Farjoun (eds), Organization at the limit: Lessons from the Columbia disaster. 101-121. Oxford: Blackwell Publishing.

Okhuysen, G.A. (2005). 'The creation and change of group routines: Learning in a SWAT team'. In Kimberly Elsbach (ed), Qualitative Organizational Research: Best Papers from the Davis 
Conference on Qualitative Organizational Research. 139-168. Greenwich, CT: Information Age Publishing.

Okhuysen, G. and Bechky, B.A. (2009). 'Coordination in organizations: An integrative perspective'. Annals of Academy of Management, 3, 463-502.

Orlikowski, W. J. 2007. Sociomaterial practices: Exploring technology at work. Organization Studies, 28, $1435-1448$.

Pentland, B.T. and Reuter, H.H. (1994). 'Organizational routines as grammars of action'. Administrative Science Quarterly 39, 484-510.

Phillips N., and Oswick, C. (2012), 'Organizational Discourse: Domains, Debates and Directions', Academy of Management Annals, 6, 435-481.

Porac, J. F., Thomas, H. and Baden-Fuller, C. (2011), 'Competitive Groups as Cognitive Communities: The Case of Scottish Knitwear Manufacturers Revisited. Journal of Management Studies', 48, 646-664.

Pratt, M.G. (2000). 'The good, the bad, and the ambivalent: Managing identification among Amway distributors'. Administrative Science Quarterly, 45, 456-493.

Pugh, S. D. (2001). 'Service with a smile: Emotional contagion in the service encounter'. Academy of Management Journal, 44, 1018-1027.

Quinn, R. and Dutton, J. (2005). 'Coordination as energy-in-conversation: A process theory of organizing’. Academy of Management Review 30, 38-57.

Quinn, R. and Worline, M.C. (2008). 'Enabling courageous collective action: Conversations from United Airlines flight 93'. Organization Science 19, 497-516.

Roberts, K.H. and Bea, R. (2001). 'Must accidents happen? Lessons from high-reliability organizations'. Academy of Management Executive 15, 70-78.

Roberts, K.H., KuoFrank Yu, Desai, V. and Madsen, P.M. (2008). 'Employing adaptive structuring as a cognitive decision aid in high reliability organizations'. In Gerard P. Hodgkinson and William H. Starbuck (eds), The Oxford Handbook of Organizational Decision Making. 194210. London: Oxford University Press.

Sacks, H., E. A. Schegloff, and Jefferson, G. (1974). 'A simplest systematics for the organization of turn-taking for conversation'. Language 50, 696-735.

Snook, S.A. (2000). Friendly fire: The accidental shoot down of U.S Black Hawks over Northern Iraq. Princeton, NJ: Princeton University Press.

Snow, D.A., Rochford, E.B., Worden, S.K. and Benford, R.D. (1986). 'Frame alignment processes, micromobilization and movement participation'. American Sociological Review, 51, 464-481.

Sonenshein, S. (2009). 'The emergence of ethical issues during strategic change'. Organization Science, 20, 223-39.

Stigliani, I., and Ravasi, D. (2012), 'Organizing Thoughts and Connecting Brains: Material Practices and the Transition from Individual to Group-Level Prospective Sensemaking'. Academy of Management Journal, 55,1232-1259. 
Strauss, A., and Corbin, J. (1990). Basics of Qualitative Research: Grounded Theory Procedures and Techniques. Newbury Park, CA: Sage Publications.

Suddaby, R. (2006). From the editors: What grounded theory is not. Academy of Management Journal, 49: 633-642.

Sweetser, E. (1990). From Etymology to Pragmatics: Metaphorical and Cultural Aspects of Semantic Structure. Cambridge: Cambridge University Press.

Tannen, D. (1985). 'Frames and schemas in interaction'. Quaderni di Semantica, 6(2), 326-335.

Taylor, J.R. and Van Every, E. (2000). The Emergent Organization: Communication as its Site and Surface. Mahwah, NJ: Lawrence Erlbaum and Associates.

Vaara, E. and Monin, P. 2010. A recursive perspective on discursive legitimation and organizational action in mergers and acquisitions. Organization Science, 21, 3-22.

Vaughan, D. (1996). The Challenger Launch Decision: Risky Technology, Culture and Deviance at NASA. Chicago, Ill: University of Chicago Press.

Walsh, I. A., and Bartunek, J. M. (2011). Cheating the Fates: Organizational foundings in the wake of demise. Academy of Management Journal 54: 1017-1044

Weick, K.E. (1988). 'Enacted sensemaking in crisis situations'. Journal of Management Studies 25, 305-17.

Weick, K. E. (1990). 'The vulnerable system: An analysis of the Tenerife air disaster'. Journal of Management 16, 571-793.

Weick, K.E. (1993a). 'The collapse of sensemaking in organizations: The Mann Gulch disaster'. Administrative Science Quarterly 38, 628-652.

Weick, K.E. (1993b). 'Sensemaking in organizations: Small structures with large consequences'. In J.K. Murnighan. (Ed.), Social Psychology in Organizations: Advances in Theory and Research. Prentice Hall, Englewood Cliffs, 10-37.

Weick, K.E. (1995). Sensemaking in Organizations. Thousand Oaks, CA: Sage.

Weick, K. E. (1996). 'Drop your tools: An allegory for organizational studies'. Administrative Science Quarterly 41, 301-313.

Weick, K.E. (2001). Making Sense of the Organization. Oxford, Blackwell Publishing.

Weick, K. E. (2007). 'The generative properties of richness'. Academy of Management Journal 50, 14-19.

Weick, K.E. (2010). 'Reflections on enacted sensemaking in the Bhopal disaster'. Journal of Management Studies 47, 537-550.

Weick, K.E. and Roberts, K.H. (1993). 'Collective mind in organizations: Heedful interrelating on flight decks'. Administrative Science Quarterly 38, 357-381.

Weick K.E. and Sutcliffe, K.M. (2003). 'Hospitals as cultures of entrapment: A re-analysis of the Bristol Royal Infirmary'. California Management Review 45, 73-84.

Weick, K.E., and Sutcliffe, K.M. (2007). Managing the Unexpected: Assuring High Performance in an Age of Complexity. San Francisco: Jossey-Bass, second edition. 
Weick, K.E., Sutcliffe, K.M., and Obstfeld, D. (1999). 'Organizing for high reliability: Processes of collective mindfulness'. Research in Organizational Behavior 21, 81- 124.

Weick, K.E., Sutcliffe, K.M., and Obstfeld, D. (2005). 'Organizing and the process of sensemaking'. Organization Science 16, 409-421.

Whiteman, G., and Cooper, W.H. (2011), 'Ecological sensemaking', Academy of Management Journal, 54, 889-911.

Wild, B., Erb, M., and Bartels, M. (2001). ,Are emotions contagious? Evoked emotions while viewing emotionally expressive faces: Quality, quantity, time course and gender differences'. Psychiatry Research, 102, 109-124.

Wilensky, R. (1986). 'Points: A theory of the structure of stories in memory'. In Barbara Grosz, Karen Jones and Bonnie Webber (eds), Readings in natural language processing. 459-473. Los Altos, CA: Morgan Kaufmann. 
Figure 1: Actors involved in the Anti-Terrorist Operation and Main Lines of Communication

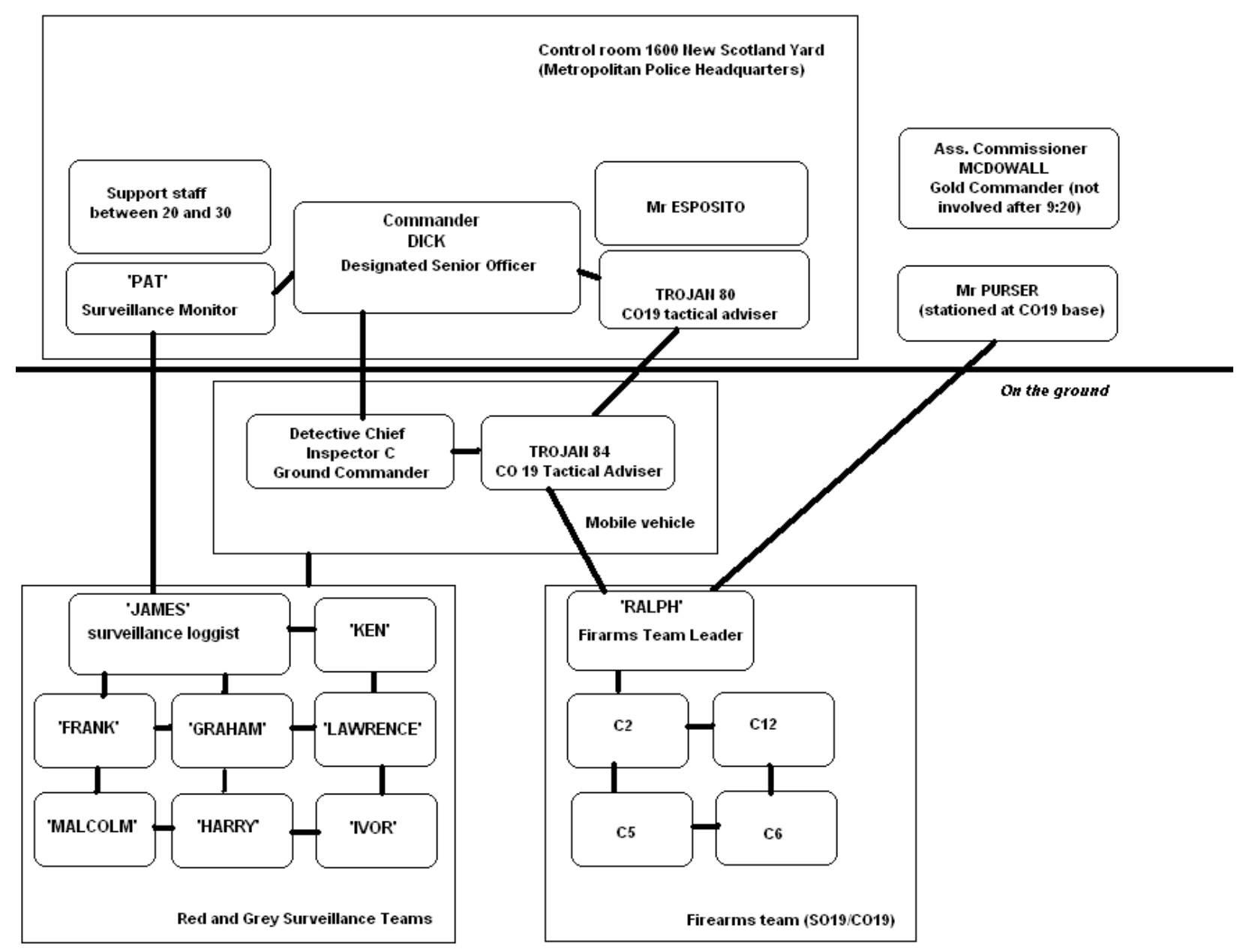


Table 1: Summary of Key Events, Sensegiving and Sensemaking Processes, and Outcomes

\begin{tabular}{|c|c|c|c|c|}
\hline Time & Event & Key actor(s) & Sensegiving and Sensemaking & Outcome(s) \\
\hline 06:00 & $\begin{array}{l}\text { First of the two surveillance teams } \\
\text { takes position }\end{array}$ & $\begin{array}{l}\text { Surveillance teams and } \\
\text { unnamed supervisor }\end{array}$ & $\begin{array}{l}\text { Surveillance officers were told to "contain" any suspects } \\
\text { leaving the premises [communication] }\end{array}$ & $\begin{array}{l}\text { Surveillance team had no authority to confront but } \\
\text { were told to "contain" suspects }\end{array}$ \\
\hline \multirow[t]{2}{*}{ 07:45 } & First briefing, firearms team & Trojan84 and firearms team & $\begin{array}{l}\text { Firearms officers told that they might have to use "unusual } \\
\text { tactics" and that they should trust the information that they } \\
\text { were given [communication] }\end{array}$ & $\begin{array}{l}\text { Expressions directly refer to the critical head shot and } \\
\text { command structure consistent with a Kratos operation }\end{array}$ \\
\hline & First briefing, firearms team & Trojan84 and firearms team & $\begin{array}{l}\text { Firearms officers issued with hollow point bullets for critical } \\
\text { headshot [material cue] }\end{array}$ & $\begin{array}{l}\text { Bullets, as a material object, signal that the operation } \\
\text { is a Kratos operation }\end{array}$ \\
\hline 08:45 & Second briefing, firearms team & Mr. Purser and firearms team & $\begin{array}{l}\text { Terrorists described as "deadly and determined", "well } \\
\text { prepared" and "up for it" [communication] }\end{array}$ & $\begin{array}{l}\text { Expressions mark the suspect(s) that they will come } \\
\text { up against as single minded terrorists }\end{array}$ \\
\hline \multicolumn{5}{|c|}{ Episode 1: the positive identification } \\
\hline \multirow[t]{2}{*}{ 09:33 } & $\begin{array}{l}\text { JCM is observed leaving the } \\
\text { building at Scotia Road }\end{array}$ & $\begin{array}{l}\text { 'Frank' and 'Edward' of the } \\
\text { red surveillance team, } \\
\text { Commander Dick and other } \\
\text { officers in the control room }\end{array}$ & $\begin{array}{l}\text { JCM is "worth a second look" and characterized as "North } \\
\text { African" [lcommunication] }\end{array}$ & $\begin{array}{l}\text { JCM is seen to warrant attention as his profile } \\
\text { corresponds with the profile of Nettle Tip }\end{array}$ \\
\hline & $\begin{array}{l}\text { JCM's is shadowed as he enters } \\
\text { the bus }\end{array}$ & $\begin{array}{l}\text { 'Harry', 'James' and 'Ken' } \\
\text { of the gray surveillance } \\
\text { team, Commander Dick and } \\
\text { other officers in the control } \\
\text { room }\end{array}$ & $\begin{array}{l}\text { JCM "acting in a wary manner and appearing nervous"; JCM } \\
\text { described as having a "good possible likeness" and being } \\
\text { "possibly identical with" the targeted suspect [material cue, } \\
\underline{\text { emotions and } \underline{\text { communication] }}}\end{array}$ & $\begin{array}{l}\text { JCM warrants further attention as his profile and } \\
\text { physical movements corresponds with the profile of } \\
\text { Nettle Tip }\end{array}$ \\
\hline 09:43 & $\mathrm{JCM}$ is observed in the bus & $\begin{array}{l}\text { 'Ivor' of the grey } \\
\text { surveillance team, } \\
\text { Commander Dick and other } \\
\text { officers in the control room }\end{array}$ & $\begin{array}{l}\text { Ivor describes JCM as "Mongolian looking" and having } \\
\text { "distinctive eyes", but not able to identify him [material cue } \\
\text { and communication] }\end{array}$ & $\begin{array}{l}\text { Apart from his racial profile, communication primes } \\
\text { the frame of identification, in line with standard } \\
\text { surveillance protocol }\end{array}$ \\
\hline \multirow[t]{2}{*}{ 09:49 } & $\begin{array}{l}\text { JCM gets off and back onto the } \\
\text { bus }\end{array}$ & $\begin{array}{l}\text { 'James' of the grey } \\
\text { surveillance team, 'Pat', } \\
\text { Commander Dick and other } \\
\text { officers in the control room }\end{array}$ & $\begin{array}{l}\text { Pat relays James' message of JCM's movements as an "anti- } \\
\text { surveillance tactic" and describing JCM's behavior as "very } \\
\text { nervous and twitchy" [material cue, emotions and } \\
\text { communication] }\end{array}$ & $\begin{array}{l}\text { Physical movements of JCM interpreted and } \\
\text { described as consistent with a profile of Nettle Tip }\end{array}$ \\
\hline & $\begin{array}{l}\text { Question about the identification } \\
\text { of JCM }\end{array}$ & $\begin{array}{l}\text { Pat, James, surveillance } \\
\text { officers, and Commander } \\
\text { Dick }\end{array}$ & $\begin{array}{l}\text { Commander Dick requests a "percentage of identification"; } \\
\text { James replies "for what it's worth, I think it's him" which Pat } \\
\text { relays in turn as } \\
\text { "It is him, the man off [the] bus. They think it is him and he is } \\
\text { very, very jumpy" [communication and emotions] }\end{array}$ & $\begin{array}{l}\text { Expressions mark a probability frame where a } \\
\text { percentage suggests the likelihood that JCM is Nettle } \\
\text { Tip } \\
\text { Expressions mark and amplify emotional stress and } \\
\text { anxiety that JCM might be Nettle Tip and lead to the } \\
\text { inference that action had to be taken }\end{array}$ \\
\hline \multicolumn{5}{|c|}{ Episode 2: the case to stop the suspect } \\
\hline \multirow{3}{*}{ 10:01 } & $\begin{array}{l}\text { Firearms team mobilized to } \\
\text { apprehend JCM }\end{array}$ & $\begin{array}{l}\text { Commander Dick, Trojan } \\
\text { 84, DCI Purser and firearms } \\
\text { officers }\end{array}$ & $\begin{array}{l}\text { Commander Dick asks DCI Purser "are you getting this?", "are } \\
\text { you getting all this?", which highlights anxiety that suspect } \\
\text { might be getting away [lcommunication and emotions] }\end{array}$ & $\begin{array}{l}\text { Order and expressions reify the positive identification } \\
\text { of JCM and the activation of Kratos protocol }\end{array}$ \\
\hline & "Stop" order & $\begin{array}{l}\text { Commander Dick, Trojan } \\
84 \text {, firearms officers }\end{array}$ & $\begin{array}{l}\text { Commander Dick orders a "stop" after discussion that suspect } \\
\text { should not be allowed to "run" [material cue and } \\
\text { communication] }\end{array}$ & $\begin{array}{l}\text { Expressions cue an image of chasing a suspect who } \\
\text { is nearing a possible target for a detonation }\end{array}$ \\
\hline & "Stop" order & Commander Dick & $\begin{array}{l}\text { Commander Dick orders a "stop" based on the realization that } \\
\text { JCM is entering the same station as the failed bombers the day } \\
\text { before [material cue] }\end{array}$ & \\
\hline
\end{tabular}


The arrival of the firearms team is signaled

Firearms officers are still not in

contention

JCM is seen picking up a Metro newspaper in the Stockwell tube station

Ivor's question relayed to the control room

James and other surveillance officers

Chf Insp Esposito, SI

Johnston, Trojan 84 an

other firearms officers

Ken, Ivor and James

James, Pat and Commande

Dick in the control room

Trojan 84, Chf Insp

Esposito, and Commander

Dick in the control room

Episode 3: containing the threat

10:03 JCM reported going down the

escalator

\section{$\mathrm{C} 2$ and $\mathrm{C} 12$ enter the station}

10:03-10:06 Surveillance officers take position on the train to direct the incoming firearms officers

Ivor stops the carriage door from closing and directs the incoming officers towards JCM

JCM rises from his seat when

officers approach him
$\mathrm{C} 2$ and $\mathrm{C} 12$

Ralph of the firearms team

and Trojan 84

Ivor, $\mathrm{C} 2$ and $\mathrm{C} 12$

Ivor, $\mathrm{C} 2$ and $\mathrm{C} 12$

James broadcasts to his team "CO19 coming through" [communication]

Chf Insp Esposito shouts "what do you mean you can't do it? Get yourself there" [communication and emotions]

Firearms officers realize that they are physically behind in the chase to catch up with the suspect [material cue

Ivor see JCM picking up a metro newspaper and asks "do you want him lifted?" [material cue and communication]

James asks Pat "Do you want him detained?" [communication]

Chf Insp Esposito confirms to Commander Dick that the

firearms officers were there [material cue and communication]

Commander Dick countermands her order and says "SO19

[are] doing [the] stop, do not let surveillance intervene" [communication.

was confirmed their mobilization

him [communication]

State red is a signal to the firearms officers that they are

required and authorized to conduct an armed intervention

[material cue]

C2 and C12 make eye contact which confirms to both men that

they are deployed [material cue]

Ivor shouts "he's here" pointing to JCM [communication and material cue]

JCM stands up, Ivor sees a potential to defuse the situation and pushes him back into his seat [material cue]

$\mathrm{C} 2$ and $\mathrm{C} 12$ see the act as an aggressive tactic and see a bulky jacket, lean over Ivor and fire eleven shots in total [material cue

$\mathrm{C} 2$ and $\mathrm{C} 12$ feel a great deal of fear and appear to panic when they fire their shots [material cue and emotions]
The surveillance team is told to make way for the firearms team when necessary

Expressions confirm again a chase and the impending danger

Ivor breaks with framing of JCM as Nettle Tip and suggests the opportunity for detaining the suspect, bringing an end to the pursuit

Expression marks the opportunity for detaining the suspect, bringing an end to the pursuit

The physical arrival of the team reinforces the set

strategy of an armed intervention

Commander Dick confirms this when she refers to the tactics associated with the Kratos frame

intervention

Ivor's expression confirms the suspect, in line with the set strategy

Ivor hints at a possible alternative to a critica headshot

C2 and C12 enact Kratos protocol 
Figure 2: Picture of Hussain Osman for the Surveillance Operation

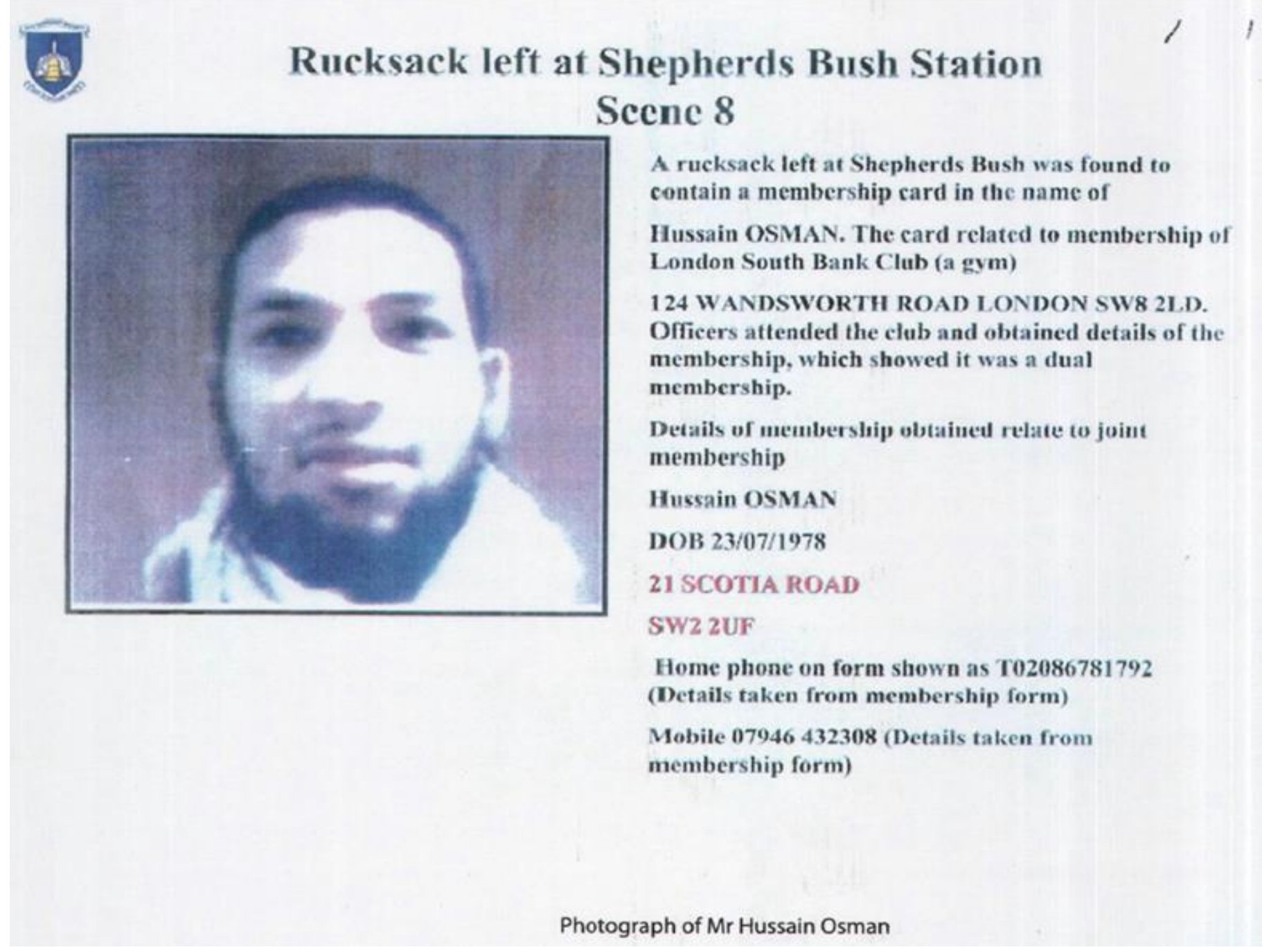




\section{Figure 3: Escalating Commitment in Sensemaking Under Pressure}

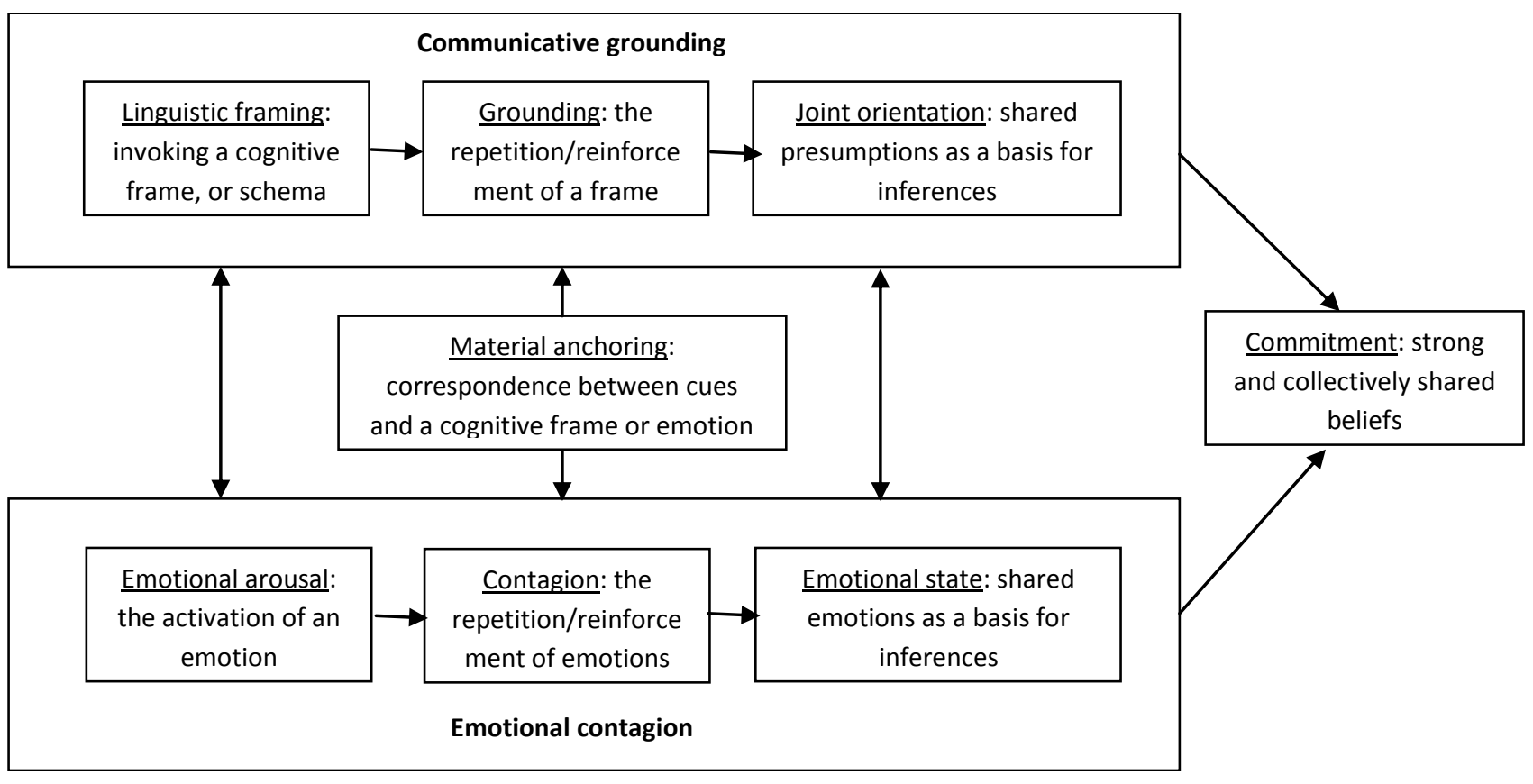

